\title{
Small Molecule Activation by Multimetallic Uranium Complexes Supported by Siloxide Ligands
}

Received 00th January 20xx, Accepted 00th January 20xx DOI: $10.1039 / x 0 \times x 00000 x$

\begin{abstract}
Luciano Barluzzi, ${ }^{\text {M Marta Falcone, }}{ }^{\text {a }}$ and Marinella Mazzanti, ${ }^{* a}$
The synthesis and reactivity of uranium compounds supported by the tris- tertbutoxysiloxide ligand is surveyed. The multiple binding modes of the tert-butoxysiloxide ligand have proven very well suited to stabilize highly reactive homo- and heteropolymetallic complexes of uranium that have shown an unusual high reactivity towards small molecules such as $\mathrm{CO}_{2}$, $\mathrm{CS}_{2}$, chalcogens and azides. Moreover, these ligands have allowed the isolation of dinuclear nitride and oxide bridged complexes of uranium in various oxidation states. The ability of the tris- tertbutoxysiloxide ligands to trap alkali ions in these nitride or oxide complexes leads to unprecedented ligand based and metal based reduction and functionalization of $\mathrm{N}_{2}$, $\mathrm{CO}$, $\mathrm{CO}_{2}$ and $\mathrm{H}_{2}$
\end{abstract}

\section{Introduction}

In the current energetic context, the search for renewable alternatives to fossil fuels is attracting increasing attention towards the chemical low energy conversion of cheap and largely available $\mathrm{C} 1$ sources such as $\mathrm{CO}_{2}$ and $\mathrm{CO}$ or $\mathrm{N}$ sources such as $\mathrm{N}_{2}$ into higher value organic molecules.

$\mathrm{CO}_{2}$ is a cheap, very largely available and renewable $\mathrm{C} 1$ source and as such, the possibility of using it in fine chemical synthesis, or converting it into liquid fuels is highly attractive. ${ }^{1} \mathrm{CO}$ is readily available as part of syngas ( $\mathrm{CO}+\mathrm{H}_{2}$, usually obtained from coal or biomass) and is used as feedstock in the industrial FischerTropsch process for production of alkanes, alkenes and alcohols. In this very energy demanding process, the reduction of $\mathrm{CO}$ by $\mathrm{H}_{2}$ is catalyzed by heterogeneous cobalt or iron catalysts under high temperatures and pressures $\left(200-350{ }^{\circ} \mathrm{C}\right.$, 20-44 bar).

Furthermore, in spite of the importance in agriculture of ammonia derived fertilizers, the only industrial process that uses dinitrogen as feedstock is the Haber-Bosch. This process is currently used for the production of large amounts of ammonia from dinitrogen and dihydrogen, but requires a metal catalyst, harsh conditions (about $450{ }^{\circ} \mathrm{C}$ and 300 bar) and consumes about $2 \%$ of the world's annual energy supply.

The sustainable transformation of small molecules such as $\mathrm{CO}_{2}$ or $\mathrm{N}_{2}$ remains a very challenging problem due to the low reactivity of such molecules. Metal complexes have been widely used to promote activation of small molecules in mild

a. al Institut des Sciences et Ingénierie Chimiques

Ecole Polytechnique Fédérale de Lausanne (EPFL),

1015 Lausanne (Switzerland)

E-mail: marinella.mazzanti@epfl.ch conditions. Uranium compounds offer an attractive alternative to metals of $s, p$ and d block. Notably, the ability of $5 f$ orbitals to participate in bonding, associated with the large size of the ion, its multiple oxidation states, and variable geometries and coordination numbers, confers unique properties and reactivity to uranium compounds rendering them a competitive perspective in catalytic application . $^{2}$ Uranium compounds have demonstrated unique reactivity in the activation of inert bonds such as $\mathrm{C}-\mathrm{H}^{3}$ and of small molecules such as $\mathrm{CO}_{2}, \mathrm{CO}, \mathrm{H}_{2}, \mathrm{H}_{2} \mathrm{O}$, $\mathrm{N}_{2}{ }^{4}$ It has also been demonstrated that uranium compounds can be implemented in synthetic cycles on the cusp of catalysis, including the remarkable transformation of $\mathrm{CO}$ and $\mathrm{H}_{2}$ into methanol in ambient conditions. ${ }^{\mathrm{ab}}, 5$ Moreover, molecular uranium compounds have been recently used to develop efficient electrocatalysts ${ }^{6}$, while uranium(III) nitride materials were reported since 1910 to act as effective catalysts for the Haber process. ${ }^{7}$ Efforts in this area have been summarized in several recent reviews. ${ }^{2 b, 4 c, 8}$ Here we just recall some examples that are most relevant for the work presented in this feature.

A few rare examples of mononuclear complexes of uranium binding $\mathrm{CO},{ }^{9} \mathrm{~N}_{2}{ }^{10}$ or $\mathrm{CO}_{2}{ }^{4 a}$ in a terminal fashion were reported (Figure 1). In the carbonyl and dinitrogen U(III) complexes, the $\mathrm{CO}$ and $\mathrm{N}_{2}$ bonds are unchanged with respect to the free molecule, suggesting a very low degree of activation. The ability of $U$ (III) complexes to bind CO contrasts with the lack of reported carbonyl complexes of $\operatorname{Ln}(\mathrm{III})$ and is interpreted in terms of a more covalent U-C interaction. In contrast, an important degree of activation is reported for the bound $\mathrm{CO}_{2}$ in the $\left[U\left\{\left({ }^{A d} A r O\right)_{3} \operatorname{tacn}\right\}\left(\eta^{1}-O C O\right)\right]$ complex, which exhibits an 
unprecedented end-on bound $\mathrm{CO}_{2}$ unit. The structural and spectroscopic data suggested the presence of a U(IV) complex of the charge-separated $\mathrm{CO}_{2}-^{-}$radical anion (U(IV)-(OCO- $\left.{ }^{-}\right)^{4 a}$ The unusual reactivity of [U\{(AdArO $\left.\left.)_{3} \operatorname{tacn}\right\}\right]$ was explained in terms of the sterical protected environment provided by the bulky ( $\mathrm{Ad} \mathrm{ArO})_{3}$ tacn system that stabilises an end-on bound $\mathrm{CO}_{2}{ }^{-}$ radical anion. This was confirmed by the reactivity of the $\mathrm{U}(\mathrm{III})$ complex of the less bulky ligand system ( $\left.{ }^{\mathrm{tBu}} \mathrm{ArO}\right)_{3}$ tacn, leading to $\mathrm{CO}_{2}$ cleavage and resulting in the formation of a very stable bridging oxo species and $\mathrm{CO} .{ }^{11}$ Beside this very unique example,

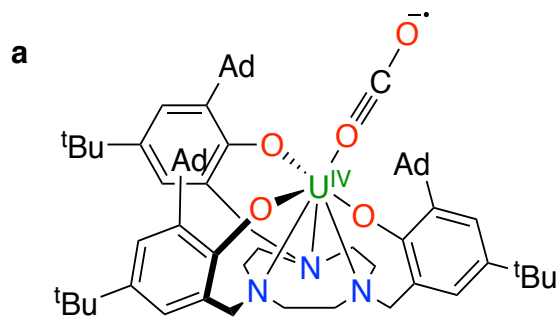

Castro-Rodriguez et al., 2004

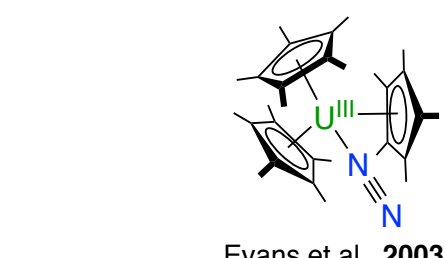

Evans et al., 2003

C

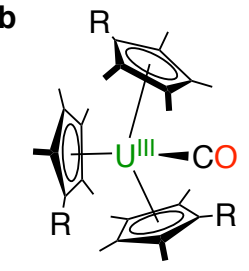

Parry et al., 1995
Figure 1 Coord nated carbond ox de to uranum na rad ca form (a), carbony complex of a U(III) compex (b), monometa c U( I) compex of $\mathrm{N}_{2}$

reduction of $\mathrm{CO}, \mathrm{CO}_{2}$ or $\mathrm{N}_{2}$ at $\mathrm{U}$ (III) centres involves, in the vast majority of reported studies, mono-electron transfer by mononuclear complexes of uranium (III). In most cases two mononuclear complexes bind the substrate and effect reduction to afford a dinuclear complex where two uranium(IV) centres are bridged by the reduced substrate. In these systems, each uranium ion is involved in one-electron transfer process. Computational studies have shown that both uranium cooperatively participate in the activation of the substrate.

In Scheme 1 and 2 some key examples of this type of reactivity with $\mathrm{CO}_{2},{ }^{12} \mathrm{CS}_{2},{ }^{13} \mathrm{CO}^{14}$ and $\mathrm{N}_{2}{ }^{15,10}$ are summarized.

Reduction of $\mathrm{CO}_{2}$ resulted in the cleavage of one $\mathrm{CO}$ bond, reductive disproportionation and reductive dimerization depending on the electronic and steric properties of the supporting ligands. $4 c, 12$

CO reduction by $U$ (III) mixed sandwich or amide complexes afforded a range of linear and cyclic homologation products $\left(\mathrm{C}_{n} \mathrm{O}_{n}\right)^{2-}$, the ethynediolate ${ }^{5 b, 14,16}(n=2)$, deltate $(n=3)^{14}$, and squarate $(n=4)^{17}$ dianions.

The reaction of two $\mathrm{U}$ (III) complexes supported by various ligands leads to side-on bridged dinitrogen complexes where the extent of dinitrogen reduction varies from $0^{15}$ to $2^{18}$ (Scheme 2). In most of these complexes $\mathrm{N}_{2}$ binding is reversible and any attempt to cleave or further functionalize the uranium bound dinitrogen resulted in $\mathrm{N}_{2}$ displacement. ${ }^{15}$, 18 These results anticipated that cooperative binding of substrates by homo- and hetero-multimetallic U(III) complexes would be

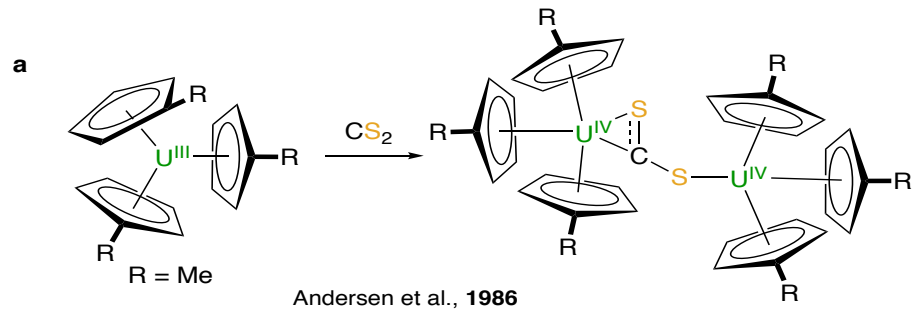

b

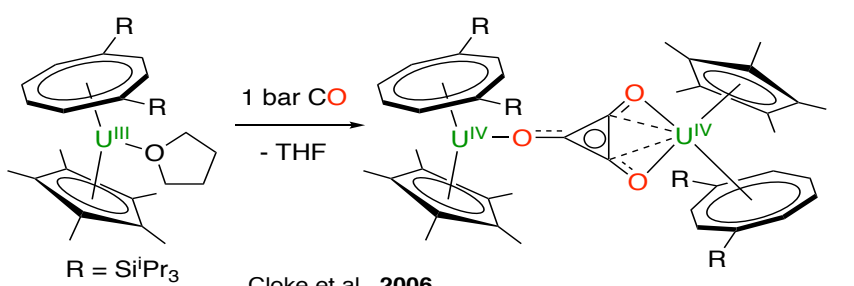

c

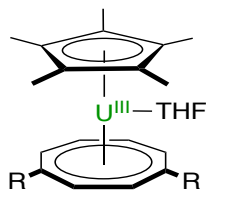

Cloke et al., 2006

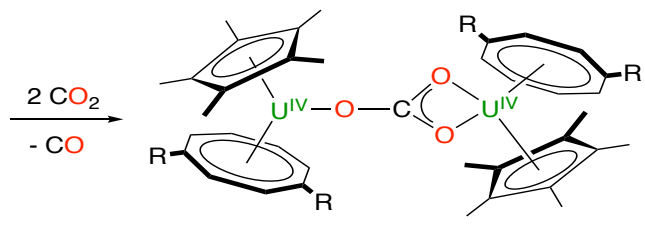

Cloke et al., 2009

Scheme 1: Carbon dsufde reduction (a), carbon monoxde reducl ve cycotrmerzaton (b) and reductve d sproportonaton of carbon doxde (c) by tr va ent uranum meta ocenes

more effective in the reduction of small molecules but examples of such systems remain extremely rare for uranium. ${ }^{4 d, 19,19 d}$ Particularly relevant is the fact that the first example of twoelectron reduction of $\mathrm{N}_{2}$ at a uranium centre was reported for a heterodimetallic U/Mo system (Scheme 3). ${ }^{19 \mathrm{~b}}$

The only example of dinitrogen cleavage reported for a uranium complex was isolated from the reduction of the U(III) complex [(Et ${ }_{8}$-calix[4]tetrapyrrole)U-(dme)][K(dme)] under nitrogen and is likely to involve a highly reactive $\mathrm{U}$ (II) intermediate. ${ }^{20}$ So far,

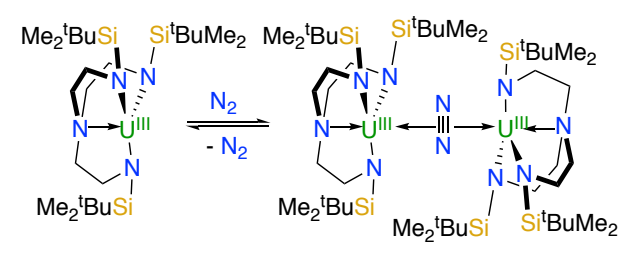

b

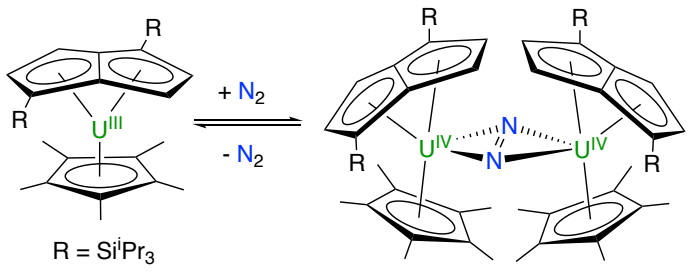

c

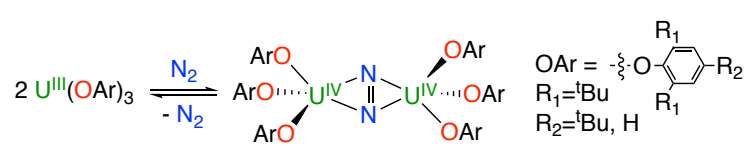

Scheme 2 Revers be coord nat on reduction of a ntrogen by $U($ i compexes s deon coord nat on (a), wo e ectron reduct on to afford the sde-on $\mathrm{N}_{2}{ }^{2-}$ bridged duranum( $V$ ) compexes win $(p$ gands (b) and arvox de gands ( $C$ ) complete cleavage of the strong $\mathrm{CO}$ and $\mathrm{N}_{2}$ triple bond by a 


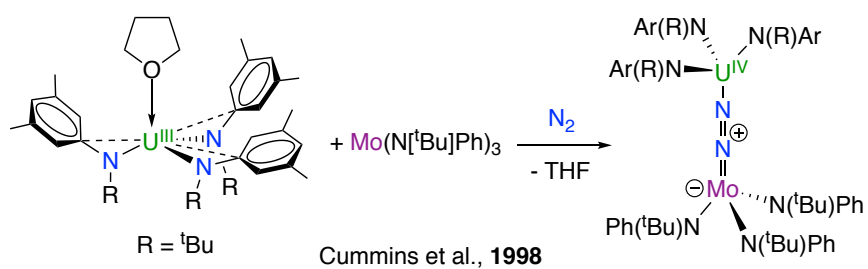

Scheme 3: Non reversible two-e ectron reduction of antrogen by an neterod meta $\& U$ Mosystem.

uranium(III) system has not been reported, but carefully tailored multimetallic complexes should be able to effect such transformations and some progresses in this direction are presented in this article.

\section{Siloxides as supporting ligands in uranium chemistry}

A broad range of siloxide ligands have been used in d-block chemistry $^{21}$ and, to some extent, in lanthanide chemistry. ${ }^{22}$ However, beside the recent work from our group featured in this article, only one additional example of the use of siloxides in uranium chemistry has been reported. ${ }^{23}$ Arnold and coworkers reported the reaction of the bulky trimesitylsilanol $\mathrm{HOSi}(\text { Mes) })_{3}\left(\mathrm{Mes}=\right.$ mesityl, 2,4,6-Me $\left.\mathrm{C}_{6} \mathrm{H}_{2}\right)$ with $\mathrm{ULN}_{3}(\mathrm{~N}=$ $\left.\mathrm{N}\left(\mathrm{SiMe}_{3}\right)_{2}\right) .{ }^{23}$ The protonolysis reaction did not allow the isolation of a siloxide supported U(III) complex, but, when performed under dinitrogen atmosphere, leads to the isolation of the dinitrogen complex $\left\{\left[U\left\{\mathrm{OSi}(\mathrm{Mes})_{3}\right\}_{3}\right]_{2}\left(\mu-\eta^{2}: \eta^{2}-N_{2}\right)\right\}$ alongside with other byproducts. The complex was shown to be very stable and to contain a reduced $\mathrm{N}_{2}{ }^{2-}$ moiety, but no reactivity of the bound $\mathrm{N}_{2}$ was reported.

\section{The tris- tertbutoxysiloxide ligand}

Tert-butoxysiloxide ligands have multiple binding modes (Figure<smiles>[M]O[Si](OCC)(OC(C)(C)C)O[Si](C)(C)C</smiles>

$\kappa^{1}$<smiles>[M]O[Si](O[M])(O[M])O[Ga]</smiles><smiles>[M]O[Si](O[M])(O[M])OCC(C)C</smiles><smiles>[M]O[Si](O[M])(O[M])O[Ga]</smiles>

$\kappa^{2} \mu^{2}$
Figure 2: Binding modes of the tris-tertbutoxysiloxide ligand.

2) and have been used extensively as supporting ligands in dblock chemistry21c, 24 and more sparsely in lanthanide chemistry 22a, 22d, 22e, 22h, 25 , but never, prior to the work of our group, in uranium chemistry. We found that tert-butoxysiloxide ligands can be used to build homopolymetallic or

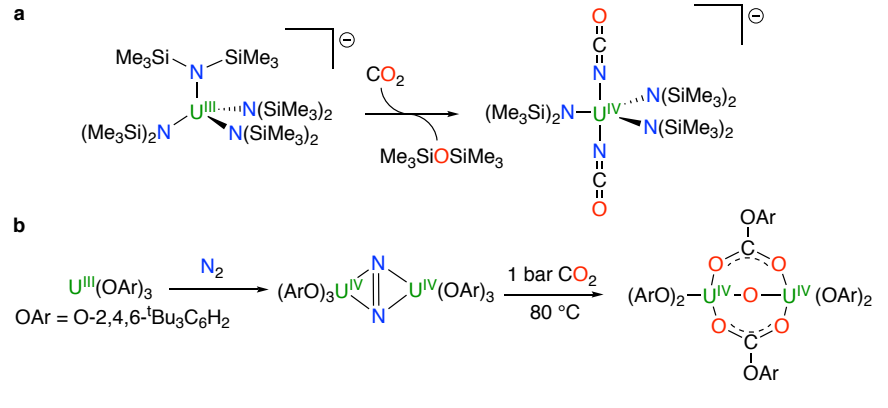

Scheme 4: $\mathrm{CO}_{2}$ nsert on react ons nto the $\mathrm{M}-\mathrm{L}$ bond.

heteropolymetallic complexes of uranium in low oxidation state. Moreover, due to their lower basicity, they are less prone to insertion of small molecules in the $M-L$ bond as found for monodentate phenoxides ${ }^{18 a}$ or amides $^{26}$ (Scheme 4). Such properties make them attractive supporting ligands for the design of metal complexes capable of promoting small molecule activation. ${ }^{4 \mathrm{~d}, 22 \mathrm{e}}$

\section{Synthesis of uranium siloxide complexes}

The homoleptic $\mathrm{U}(\mathrm{IV})$ complex $\left[\mathrm{U}\left(\mathrm{OSi}(\mathrm{OtBu})_{3}\right)_{4}\right], \mathbf{1}$ is easily obtained from the reaction of $\left[\mathrm{UI}_{4}\left(\mathrm{OEt}_{2}\right)_{2}\right]$ with the potassium salt of the tris-tertbutoxysiloxide ligand (Scheme 5). ${ }^{27}$ The solidstate structure of crystals of $\mathbf{1}$, isolated from hexane ${ }^{4 d}$, clearly shows the ability of the siloxide to act as a polydentate supporting ligand in the absence of coordinating solvents or other substrates. The structure of $\mathbf{1}$ isolated from THF or pyridine shows that the butoxy oxygen atom can be easily displaced by coordinating substrates such as THF or pyridine. ${ }^{27}$ The reaction of 1 with 1 equiv of $\mathrm{KC}_{8}$ at room temperature leads to the formation of the neutral heterodimetallic U(III) "ate" complex $\left[\mathrm{KU}\left(\mathrm{OSi}\left(\mathrm{O}^{\mathrm{t}} \mathrm{Bu}\right)_{3}\right)_{4}\right], 2$. This complex is stable in solid state and in solution up to $100^{\circ} \mathrm{C}$. ${ }^{1} \mathrm{H}$ NMR studies showed that the potassium cation remains bound in toluene solution in the pocket formed by the oxygen atoms of the siloxide ligands confirming the heterodimetallic nature of the "ate" complex $\mathbf{2}$. Addition of crown ether to $\mathbf{2}$ affords the ion-pair analogue $[\mathrm{K}(18 \mathrm{c} 6)]\left[\mathrm{U}\left(\mathrm{OSi}\left(\mathrm{O}^{\mathrm{t} B u}\right)_{3}\right)_{4}\right], 3 .{ }^{19 \mathrm{a}}$

The homoleptic dinuclear complex of $\mathrm{U}(\mathrm{III})\left[\mathrm{U}\left(\mathrm{OSi}\left(\mathrm{O}^{\mathrm{t}} \mathrm{Bu}\right)_{3}\right)_{3}\right]_{2}, 4$, can be synthesised in high yield from the metathesis reaction of

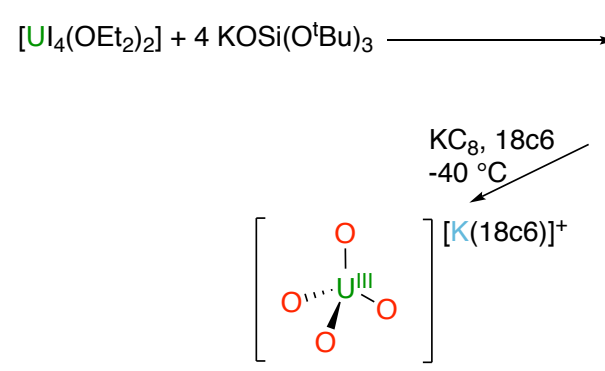

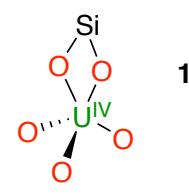

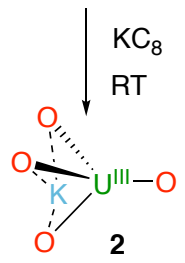

Scheme 5: Synthess of the homoeptc compex $\left[\cup\left(\mathrm{OS}\left(\mathrm{O}^{t} \mathrm{Bu}\right)_{3}\right)_{4}\right], 1$ and its reduct on react ons performed $n$ presence or absence of crown ether to afford the heterodimetallic complex $\mathbf{2}$ or the ion-pair analogue, 3, respectively. 
the tris amide complex $\left[\mathrm{U}\left(\mathrm{N}\left(\mathrm{SiMe}_{3}\right)_{2}\right)_{3}\right]$ with the silanol ligand (Scheme 6). ${ }^{4 d}$ This dinuclear complex is stable in the solid state and in hexane at $-40^{\circ} \mathrm{C}$, but decomposes slowly at room temperature.

Decomposition is fast when the solid is heated at $80^{\circ} \mathrm{C}$ affording
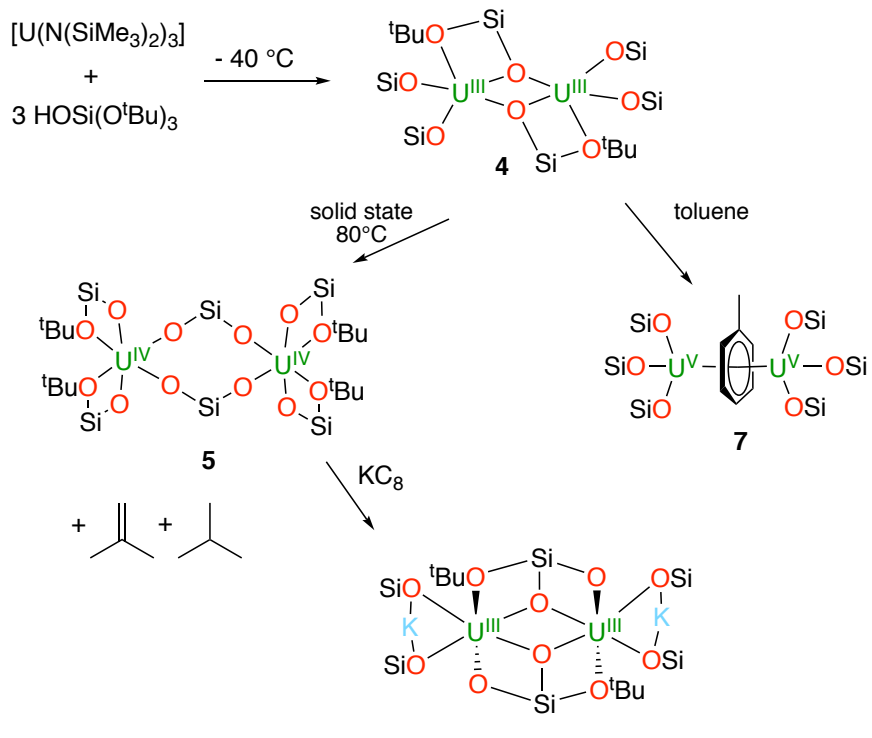

6

Scheme 6: Synthess of the homoeptc dinuclear complex of $U(I I I)$, $\left[\mathrm{U}\left(\mathrm{OSi}(\mathrm{OtBu})_{3}\right)_{3}\right]_{2}, 4$. The decomposition of $\mathbf{4}$ in solid state leads to the s ox de s and o ate duranum( $V$ ) compex, 5 , whch s further reduced to the diuranium(III) analogue, 6 . Complex 4 reduces to vene to ve d the duran um( $V$ ) inverse sandwich complex 7 (Tertbutv groups of unbound tertbutox de groups are omitted).

the dinuclear $\mathrm{U}(\mathrm{IV})$ complex $\left[\mathrm{U}\left(\mathrm{OSi}\left(\mathrm{O}^{\mathrm{t}} \mathrm{Bu}\right)_{3}\right)_{2}\left(\mu-\mathrm{O}_{2} \mathrm{Si}\left(\mathrm{O}^{\mathrm{t}} \mathrm{Bu}\right)_{2}\right)\right]_{2}, \mathbf{5}$. The formation of $\mathbf{5}$ from $\mathbf{4}$ involves the oxidative cleavage of two tertbutyl groups from the siloxide ligand affording a new dianionic silandiolate ligand. ${ }^{28}$ The heteroleptic complex $\mathbf{5}$ can be reduced with potassium to afford the new $\mathrm{U}(\mathrm{III})-\mathrm{U}(\mathrm{III})$ complex $\left[\mathrm{K}(\mathrm{THF}) \mathrm{U}\left(\mathrm{OSi}\left(\mathrm{O}^{\mathrm{t}} \mathrm{Bu}\right)_{3}\right)_{2}\left(\mu-\mathrm{O}_{2} \mathrm{Si}\left(\mathrm{O}^{\mathrm{t}} \mathrm{Bu}\right)_{2}\right)\right]_{2} 6$ in high yield. Complex 6 is the first example of a U(III) complex containing both siloxide and silandiolate ligands, and provides a potential precursor for reactivity studies.

The diuranium(III) siloxide complex $\mathbf{4}$ is also unstable in toluene, where clean reduction of toluene occurs to afford the inverted arene sandwich $\left[\left\{\mathrm{U}\left(\mathrm{OSi}\left(\mathrm{O}^{\mathrm{t}} \mathrm{Bu}\right)_{3}\right)_{3}\right\}_{2}\left(\mu-\eta^{6}: \eta^{6}-\mathrm{C}_{7} \mathrm{H}_{8}\right)\right], 7$ which was identified as the product of four-electron reduction of toluene $\left(U(V)-(\text { arene })^{4-}-U(V)\right)$. Complex 4 dissociates in coordinating solvents (THF) to afford the mononuclear solvate analogue.

The complexes $\mathbf{2}, \mathbf{3}$ and $\mathbf{4}$ provide a versatile platform to investigate cooperative effects in small molecule activation by U(III) complexes.

\section{Reactivity of siloxides-supported uranium complexes}

\section{Reaction with heteroallenes $\left(\mathrm{CO}_{2}\right.$ and $\left.\mathrm{CS}_{2}\right)$}

In scheme $\mathbf{7}$ are summarized the reactions of the complexes $\mathbf{2}$, 3 and 4 with $\mathrm{CS}_{2}$. The dinuclear complex $\left[\mathrm{U}\left(\mathrm{OSi}\left(\mathrm{O}^{\mathrm{t}} \mathrm{Bu}\right)_{3}\right)_{3}\right]_{2}, \mathbf{4}$, effects the two-electron reaction of $\mathrm{CS}_{2}$ in ambient conditions to afford $\left[\left\{\mathrm{U}\left(\mathrm{OSi}\left(\mathrm{O}^{\mathrm{t}} \mathrm{Bu}\right)_{3}\right)_{3}\right\}_{2}\left\{\mu-\mathrm{CS}_{2}\right\}\right], 8^{4 d}$ where the $\mathrm{CS}_{2}{ }^{2-}$ ligand bridges two $U(I V)$ centres in a $\operatorname{rare}^{29} \mu-\eta^{2}(C, S 1): \eta^{2}(S 1, S 2)$

a

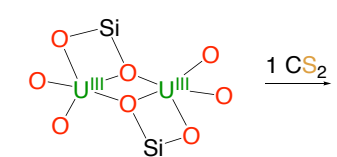

4

b

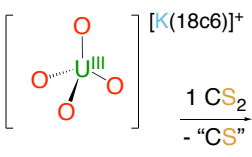

3

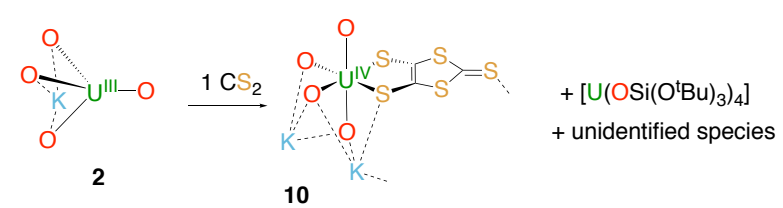

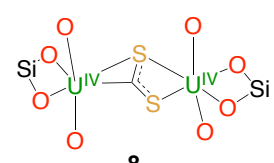

8

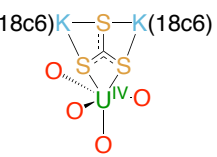

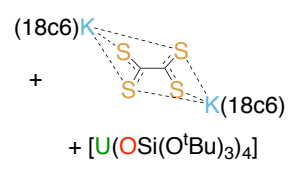

+ unidentified species
Scheme 7: Reduction of $\mathrm{CS}_{2}$ (a) by 4 to give the bridging $\mathrm{CS}_{2}{ }^{2-}$ diuranium(IV) complex 8 , (b) by 3 and (c) by 2 (Onv the the bound oxvgen atoms of thes ox des are shown here and $n$ the fo owng schemes).

fashion. This is only the second example of a diuranium(IV) complex bridged by a $\mathrm{CS}_{2}{ }^{2-}$ ligand. The $\left[\left(\mathrm{RC}_{5} \mathrm{H}_{4}\right)_{3} \mathrm{U}\right]_{2}\left[\mu-\eta^{1}: \eta^{2}-\mathrm{CS}_{2}\right]$ complex was obtained from the reduction of $\mathrm{CS}_{2}$ by the $\mathrm{U}$ (III) complex $\left[\left(\mathrm{RC}_{5} \mathrm{H}_{4}\right)_{3} \mathrm{U}\right] .{ }^{13}$

In contrast, Meyer et al. reported the formation of a mixture of trithiocarbonate and a tetrathiooxalate complexes from reduction of $\mathrm{CS}_{2}$ by the trivalent uranium complex of a multidentate phenolate $\left.\left[(\mathrm{Ad} A \mathrm{ArO})_{3} \mathrm{~N}\right) \mathrm{U}(\mathrm{DME})\right] .{ }^{30}$ DFT studies on these phenolate systems identified a $\mathrm{CS}_{2}{ }^{2-}$ bridged $\mathrm{U}(\mathrm{IV}) / \mathrm{U}(\mathrm{IV})$ dimer as the most reasonable intermediate in the formation of trithiocarbonate and tetrathiooxalate, ${ }^{31}$ but this intermediate was not experimentally observed. In contrast, DFT studies indicated that complex 8 is the most stable product of the reaction of 4 with 1equiv of $\mathrm{CS}_{2}$ and that any further reaction from the bimetallic complex $\mathbf{8}$ to yield sulfide, thiocarbonate or tetrathiooxalate complexes are either thermodynamically or kinetically unfavourable, in agreement with the experimental observation of the complex $\mathbf{8}$ as the only product. ${ }^{4 d}$

However, when the number of siloxide ligands bound to the uranium(III) centres is increased from 3 to 4 , the reaction with $\mathrm{CS}_{2}$ proceeds differently, leading to the formation of the reductive coupling and disproportionation products that are rapidly released from the coordination sphere of the metal centre due to the steric bulkiness of the "ate" complexes. ${ }^{32}$ The "ate" complex 3, and the heterodimetallic $\mathbf{2}$ both effect the parallel reductive dimerization and reductive disproportionation of $\mathrm{CS}_{2}$. However, ${ }^{13} \mathrm{C}$ NMR studies show that the presence of the bound Lewis acidic potassium cation in $\mathbf{2}$ leads preferentially to the reductive dimerization of $\mathrm{CS}_{2}$, while the reductive disproportionation pathway is favoured by the "ate" complex 3. The unstable intermediates $\left[\mathrm{U}\left(\mathrm{OSi}\left(\mathrm{O}^{t} \mathrm{Bu}\right)_{3}\right)_{4}\left(\mu_{3-}\right.\right.$ $\left.\left.\mathrm{CS}_{3}\right) \mathrm{K}_{2}(18 \mathrm{c} 6)_{2}\right], 9$ and $\left[\mathrm{U}\left(\mathrm{OSi}\left(\mathrm{O}^{\mathrm{t}} \mathrm{Bu}\right)_{3}\right)_{4} \mathrm{~K}_{2}\left(\mathrm{C}_{3} \mathrm{~S}_{5}\right)\right]_{\mathrm{n}} 10$ containing bound trithiocarbonate, and bound dmit dianion ( $\mathrm{dmit}^{2-}=\mathrm{C}_{3} \mathrm{~S}_{5}{ }^{2-}$ $=1,3$-dithiole-2-thione-4,5-dithiolate, formed from the reaction 
of $\mathrm{C}_{2} \mathrm{~S}_{4}{ }^{2-}$ with $\mathrm{CS}$ ) were isolated and crystallographically characterized. ${ }^{32}$

The terminal trithiocarbonate 9 was found to rapidly release the $\mathrm{K}_{2} \mathrm{CS}_{3}$ substrate, rendering the system attractive for the development of catalytic cycles. ${ }^{32}$ The differences in reactivity between complexes $\mathbf{3}$ and $\mathbf{2}$ were interpreted in terms of different multimetallic U-K cooperativity. In contrast, the lower stability of the putative $\mathrm{CS}_{2}{ }^{2-}$ intermediates is probably the result of combined electronic and steric factors introduced by the additional electron-rich, bulky siloxide present in $\mathbf{3}$ and $\mathbf{2}$ compared to 4.

$\mathrm{CO}_{2}$ also reacts in ambient conditions with complexes $\mathbf{2}, \mathbf{3}$ and 4. The reactions are summarized in Scheme 8.

The dinuclear tris-siloxide complex 4 effects the reductive disproportionation of $\mathrm{CO}_{2}$ to afford the carbonate-bridged diuranium(IV) complex $\left[\left\{\mathrm{U}\left(\mathrm{OSi}\left(\mathrm{O}^{\mathrm{t}} \mathrm{Bu}\right)_{3}\right)_{3}\right\}_{2}\left\{\mu-\eta^{1}: \eta^{2}-\mathrm{CO}_{3}\right\}\right], \mathbf{1 1}$, and

a

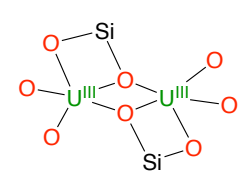

4

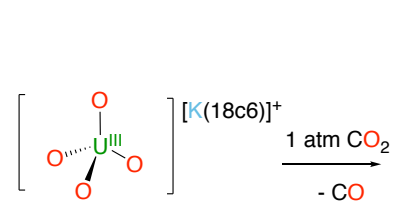

3

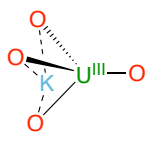

$\underset{-\mathrm{CO}}{\stackrel{1 \mathrm{~atm} \mathrm{CO}_{2}}{\longrightarrow}}$

2

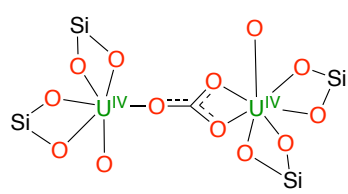

11

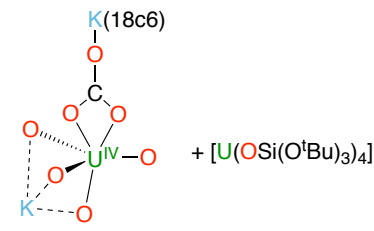

12

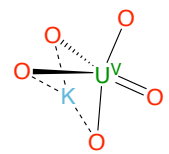

13
Scheme 8: Carbon d ox de reduct on react ons by the d nuc ear $U$ ( ) comp ex 4 to g ve the br dg $\mathrm{ng}$ carbonate a nucear $U(V)$ compex 11 (a); carbon dioxide reduction by the ate and the heterob meta c compexes 3 and 2, to give the $U$ (IV) carbonate complex 12 (b) and the U(V) term na oxo comp ex 13 (c).

$\mathrm{CO} .{ }^{4 d}$ The reductive disproportionation of $\mathrm{CO}_{2}$ to $\mathrm{CO}$ and uranium carbonate derivatives had been previously reported for mixed sandwich $\mathrm{U}(\mathrm{III}),{ }^{12}$ and tris(aryloxide) systems. ${ }^{5 \mathrm{a}}, 33$ However, the reaction mechanism proposed for the reaction of 4 with $\mathrm{CO}_{2}$, on the base of DFT computational studies, differs significantly from the previously reported systems. In the case of mononuclear U(III) complexes of polydentate tris(aryloxide) and mixed sandwich ligands, a diuranium(IV) oxo bridged intermediate was postulated to form upon extrusion of $\mathrm{CO}$ from a bimetallic intermediate species [U(IV)]-( $\left.\mathrm{CO}_{2}{ }^{2-}\right)-[\mathrm{U}(\mathrm{IV})]$. The oxo dimer further inserts a second $\mathrm{CO}_{2}$ molecule to afford the final carbonate. ${ }^{34}$ In contrast, in the case of $\mathbf{4}$ the carbonate complex formation occurs through an alternative mechanism where the attack of $\mathrm{CO}_{2}$ and release of $\mathrm{CO}$ are concerted. ${ }^{4 \mathrm{~d}}$

This concerted mechanism of $\mathrm{CO}_{2}$ reduction is probably favoured by the dinuclear nature of complex 4 , which is, so far, the only dinuclear complex of uranium reported to activate $\mathrm{CO}_{2}$. The reactivity of $\mathbf{4}$ with carbon dioxide contrasts with that reported for mononuclear uranium(III) complexes supported by monodentate aryloxide or amide ligands for which no carbonate adducts were isolated and multiple reduction and insertion products were identified. ${ }^{18 a}$, 26 This could be ascribed to the different electronic and steric properties of the siloxide supporting ligand confirming their interest as alternative ancillary ligand in $\mathrm{U}(\mathrm{III})$ chemistry. However, the role of the dimetallic nature of complex $\mathbf{4}$ should not be underestimated. The ion pair complex 3 readily reacts in ambient condition with $\mathrm{CO}_{2}$ to afford $\mathrm{CO}$, the terminal $\mathrm{U}(\mathrm{IV})$ carbonate complex $\left[(18 \mathrm{c} 6) \mathrm{K}\left(\mu-\eta^{1}: \eta^{2} \mathrm{CO}_{3}\right) \mathrm{U}\left(\mathrm{OSi}\left(\mathrm{O}^{\mathrm{t} B u}\right)_{3}\right)_{4} \mathrm{~K}\right], \quad \mathbf{1 2}$, and the $\mathrm{U}(\mathrm{IV})$ complex $\mathbf{1}$. Complex $\mathbf{1 2}$ shows higher stability compared to $\mathbf{1 1}$ with respect to ligand scrambling over time in toluene solution. The presence of the coordinating $[\mathrm{K}(18 \mathrm{c} 6)]^{+}$cation binding the carbonate group may play a role in the stabilization of the mononuclear product. ${ }^{19 a}$

Thus, both the dinuclear tris-siloxide complex $\mathbf{4}$ and the mononuclear tetrasiloxide complex $\mathbf{3}$ promote selectively the reductive disproportionation of $\mathrm{CO}_{2}$. This reactivity is remarkably different from the reactivity with $\mathrm{CS}_{2}$. Notably, the tris-siloxide 4 leads to a stable $\left[\left\{\mathrm{U}\left(\mathrm{OSi}(\mathrm{OtBu})_{3}\right)_{3}\right\}_{2}\left\{\mu-\mathrm{CS}_{2}{ }^{2-}\right\}\right]$ intermediate, while both reductive disproportionation and reductive dimerization of $\mathrm{CS}_{2}$ were observed with the bulky tetrasiloxide complex 3 . The pathway leading to reductive dimerization of $\mathrm{CO}_{2}$ to oxalate was not observed for $\mathbf{3}$. Oxalate formation from $\mathrm{CO}_{2}$ is rare and only three examples have been reported for uranium(III) that were obtained as the kinetic products of the reaction controlled by steric effects. ${ }^{35}$ In contrast, the heterodimetallic complex $\mathbf{2}$ shows a dramatically different and unprecedented (in uranium chemistry) reactivity with $\mathrm{CO}_{2}$. Complex 2 effects the two-electron reduction of $\mathrm{CO}_{2}$ in ambient conditions leading to the terminal $\mathrm{U}(\mathrm{V})$ oxo complex $\left[\mathrm{UO}\left(\mathrm{OSi}\left(\mathrm{O}^{\mathrm{t} B u}\right)_{3}\right)_{4} \mathrm{~K}\right], 13$ and $\mathrm{CO} .{ }^{19 a}$ This reaction is the first example of the two-electron reductive cleavage of $\mathrm{CO}_{2}$ mediated by a single $\mathrm{U}$ (III) complex. One example of twoelectron reductive cleavage of $\mathrm{CO}_{2}$ had been previously reported but involved the concerted oxidation of two $\mathrm{U}(\mathrm{III})$ complexes. ${ }^{11}$ Notably, addition of carbon dioxide to the $\mathrm{U}$ (III) complex [( ( $\left.\left.\left.{ }^{\mathrm{Bu}} \mathrm{ArO}\right)_{3} \mathrm{tacn}\right) \mathrm{U}\right]$ resulted in the formation of an oxobridged diuranium(IV) species with extrusion of carbon monoxide. In general, all previously reported examples of $\mathrm{CO}_{2}$ reduction by $\mathrm{U}$ (III) complexes involved two metal complexes transferring one electron each. ${ }^{4 c,} 35-36$ The reactivity of the heterodimetallic complex $\mathbf{2}$ is remarkable both because twoelectron redox transfer is generally rare in uranium chemistry ${ }^{27}$, 37 and terminal $U(\mathrm{~V})$ oxo complexes are not common. Notably, the formation of terminal uranium(V) oxo complexes from the reaction of $U($ III) with oxo-transfer reagents requires the use of bulky ligands preventing the formation of more stable dinuclear oxo-bridged U(IV) complexes and a careful choice of the oxotransfer agents. ${ }^{38} \mathrm{U}(\mathrm{V})$ mono-oxo complexes have also been obtained by the reductive cleavage of nitrite by a U(IV) complex, ${ }^{39}$ and from the metathesis of a $\mathrm{U}(\mathrm{V})$-imido complex with $\mathrm{CO}_{2} .{ }^{40}$ The dramatic difference in the reactivity of complexes $\mathbf{2}$ and $\mathbf{3}$ with carbon dioxide was explained in terms of the presence of a coordinated potassium cation in proximity to the uranium centre in complex $\mathbf{2}$. The association of a highly 
reducing $\mathrm{U}$ (III) ion and an electropositive potassium cation is likely to result in the cooperative binding and activation of carbon dioxide. A similar coordination mode has been characterized at a Col-M (M= Li, Na) site. ${ }^{41}$ DFT studies support the significant influence of the potassium atom as well as the cooperative effect between the metal centres in $\mathrm{CO}_{2}$ transformation. ${ }^{19 a}$

\section{Reaction with chalcogen transfer reagents; synthesis of chalcogenide complexes}

Activation of chalcogens and functionalization of chalcogenides is attracting increasing interest in uranium chemistry ${ }^{42}$ due to its relevance in catalysis and in spent nuclear fuel processing. However, examples of activation of elemental chalcogens by uranium compounds remain relatively scarce and have mostly

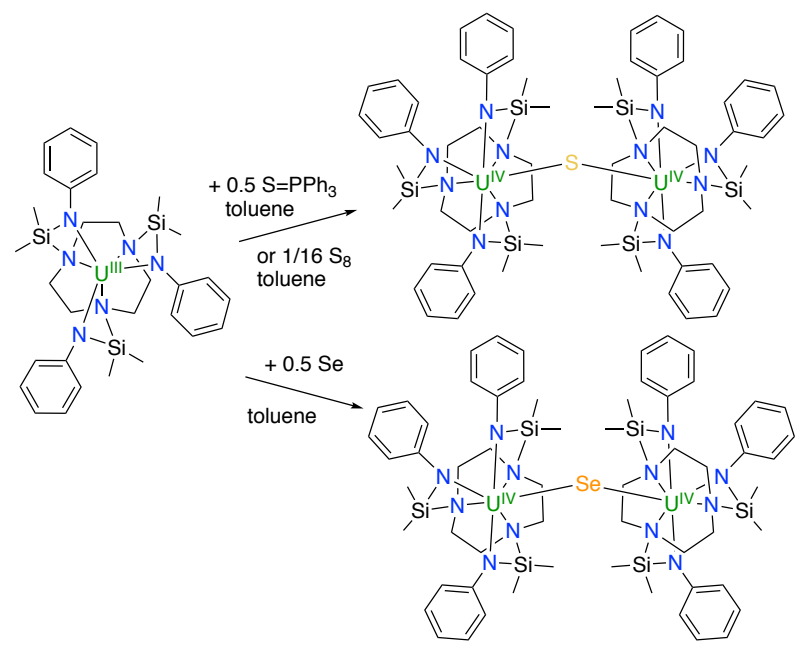

Scheme 9: Synthesis of sulfide-bridged and selenide-bridged complexes of U(IV) with the tacn-based ligand system.

resulted in the single electron oxidation of the uranium centre even in the presence of an excess of chalcogen, which is formally a two-electron oxidizing agent. Notably, U(III) mononuclear complexes are known to promote the reduction of elemental sulfur providing a pathway to sulfide bridged diuranium(IV) complexes (Scheme 9 shows a representative example from ref ${ }^{37 a}$ ). $37 a, 43$ In contrast, the reaction of a dinuclear U(III) complex with excess sulfur was reported to lead to a persulfide bridged diuranium(IV) complex. ${ }^{19 \mathrm{c}}$ The formation of the persulfide versus sulfide species could be explained by a cooperative binding of sulfur by the two metal centres associated to simultaneous one electron transfer, while the reaction of mononuclear $\mathrm{U}(\mathrm{III})$ complexes is likely to proceed via the formation of a terminal $U(V)$ sulfide that further reacts with another U(III) complex. The first terminal U(IV) sulfide was reported by Hayton and coworkers by using a ylide protecting group that disfavours the formation of bridging sulfide complexes during sulfur transfer from $\mathrm{S}_{8}$ to $\mathrm{U}$ (III) amido complex. ${ }^{44}$ Single electron chalcogen reduction was also reported for dimeric bis(imido) $U(V)$ complexes leading to the formation of $E^{2-}$ or $\left[E_{4}\right]^{2-}(E=S$, Se) bridged diuranium(VI) complexes. ${ }^{45}$
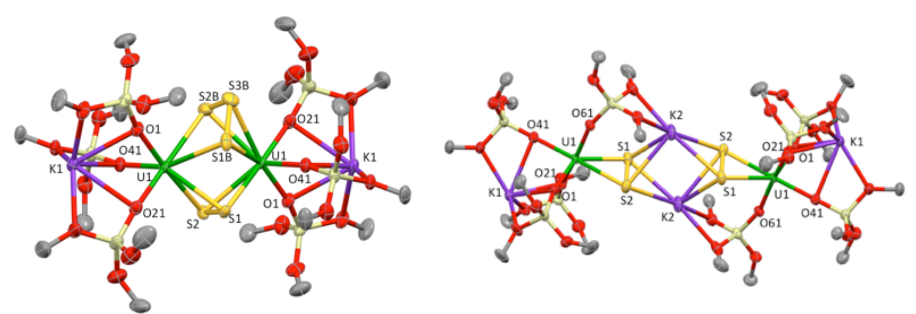

Figure 3: Moecuar structure of the ir su fde compex 14 (left) and the disulfide complex 15 (right).

The use of bulky ligands has often been employed to favour the formation of terminal sulfide complexes. However, the reaction of $\left[\mathrm{KU}\left(\mathrm{OSi}\left(\mathrm{O}^{\mathrm{t} B u}\right)_{3}\right)_{4}\right], 2$ with 0.125 equiv $\mathrm{S}_{8}$ leads to a complex mixture of compounds from which the disulfide

a

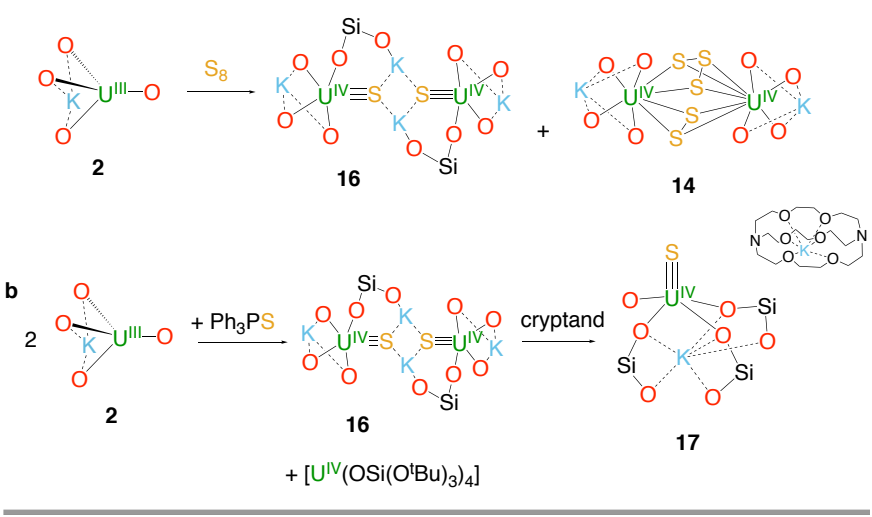

Scheme 10: React ons of the heterod meta c comp ex 2 with $\mathrm{S}_{8}(\mathrm{a})$ and $\mathrm{Ph}_{3} \mathrm{PS}(\mathrm{b})$ yielding the $U(I V)$ potassium-capped sulfide, 16 complex and the $U(I V)$ non-capped sulfide complex, 17

$\left[\mathrm{K}_{2} \mathrm{U}\left(\mathrm{S}_{2}\right)\left(\mathrm{OSi}\left(\mathrm{O}^{\mathrm{t} B u}\right)_{3}\right)_{4}\right]_{2}, \quad 14$ and the trisulfide $\left[\mathrm{K}\left(\mu-\mathrm{S}_{2}\right)(\mu-\right.$ $\left.\left.\mathrm{S}_{3}\right)\left\{\mathrm{U}\left(\mathrm{OSi}\left(\mathrm{O}^{\mathrm{t} B u}\right)_{3}\right)_{3}\right\}_{2}\right]_{2}, 15$ diuranium(IV) dimer were isolated ${ }^{46}$ (Figure 3).

In contrast, a rare potassium capped $\left(\left[\mathrm{SU}\left(\mathrm{OSi}\left(\mathrm{O}^{t} \mathrm{Bu}\right)_{3}\right)_{4} \mathrm{~K}_{2}\right]_{2}\right), 16$ or non-capped ([SU(OSi $\left.\left.\left(\mathrm{O}^{\mathrm{t} B u}\right)_{3}\right)_{4} \mathrm{~K}\right][$ Kcryptand]), $17 \mathrm{U}(\mathrm{IV})$ terminal sulfide, (Scheme 10) could be selectively formed by reacting 2 with $\mathrm{Ph}_{3} \mathrm{PS}$ with or without the presence of cryptand. 46

Interestingly, if $\mathbf{2}$ is pre-treated with cryptand, no reaction is observed whit $\mathrm{Ph}_{3} \mathrm{PS}$, which unambiguously demonstrated that the presence of a bound potassium cation is crucial in the Stransfer reaction between $\left[\mathrm{U}\left(\mathrm{OSi}\left(\mathrm{O}^{t} \mathrm{Bu}\right)_{3}\right)_{4} \mathrm{~K}\right]$ and $\mathrm{Ph}_{3} \mathrm{PS}$. This dramatic difference in reactivity was explained in terms of steric differences leading to a reduced access of the $S_{8}$ substrate to the metal centre. However, cooperative binding of uranium and 
potassium centre to the sulfur are likely to play an important role in reactivity.

A few studies of the reactivity of bridging and terminal chalcogenides have been reported with different ancillary

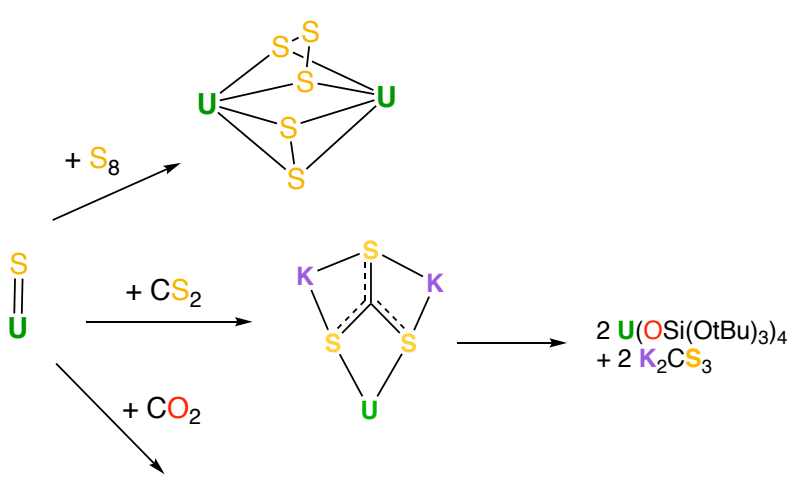

$\cos$

Scheme 11: React viv of the capped and term na su fdes win $S_{8}, \mathrm{CS}_{2}$ and ligands. Terminal ${ }^{47}$ and bridging ${ }^{48}$ chalcogenides were reported to further activate elemental chalcogens to afford terminal and bridging polychalcogenido uranium complexes respectively. The activation of $\mathrm{CS}_{2}, \mathrm{CO}_{2}$, and $\mathrm{COS}$ by chalcogenide-bridged complexes has also been reported for the $\left[\left\{\left((\operatorname{Ad} A r O){ }_{3} N\right) U\right\}_{2}(\mu-\right.$ $\mathrm{E})](\mathrm{E}=\mathrm{S}, \mathrm{Se})$ and leads to trithiocarbonate bridged $\left[\left\{\left((\mathrm{AdArO})_{3}\right.\right.\right.$ N)U $\left.\}_{2}\left(\mu-\kappa_{2}: K_{2}-C_{3}\right)\right]^{31}$ and mixed-chalcogeno carbonate bridged complexes of the types $\mathrm{U}-\mathrm{CO}_{2} \mathrm{E}-\mathrm{U}(\mathrm{E}=\mathrm{S}, \mathrm{Se}), \mathrm{U}-\mathrm{CS}_{2} \mathrm{E}-\mathrm{U}(\mathrm{E}=\mathrm{O}$, $\mathrm{Se})$, and U-COSSe-U.49

In our group, we investigated the reactivity of the capped and terminal sulfides with $\mathrm{S}_{8}, \mathrm{CS}_{2}$ and $\mathrm{CO}_{2}$ (Scheme 11). Excess sulfur leads to polychalcogenide-bridged complexes as a result of loss of one siloxide ligand, but the reaction with $\mathrm{CS}_{2}$ leads to the formation of terminal trithiocarbonate complexes that release the bound $\mathrm{K}_{2} \mathrm{CS}_{3}$ over time. The trithiocarbonate intermediate complex $\left[\mathrm{U}\left(\mathrm{OSi}\left(\mathrm{O}^{\mathrm{t}} \mathrm{Bu}\right)_{3}\right)_{4}\left(\mu_{3}-\kappa^{2}: \kappa^{2}: \kappa^{2}-\mathrm{CS}_{3}\right) \mathrm{K}_{2}(18 \mathrm{c} 6)_{2}\right], 9$, was isolated and crystallographically characterized from the direct reaction of the ion-pair complex $[\mathrm{K}(18 \mathrm{c} 6)]\left[\mathrm{U}\left(\mathrm{OSi}\left(\mathrm{O}^{\mathrm{t} B u}\right)_{3}\right)_{4}\right], \mathbf{3}$, with $\mathrm{CS}_{2} .{ }^{32}$ The reaction of the terminal sulfide 17 with $\mathrm{CO}_{2}$ leads to free COS probably from the decomposition of a U(IV)$\mathrm{CO}_{2} \mathrm{~S}$ intermediate. ${ }^{46}$

Surprisingly, $U(V)$ terminal sulfides could not previously be obtained from the activation of $\mathrm{S}_{8}$ by $\mathrm{U}$ (III) complexes, probably due to the high nucleophilic nature of such compounds that results in fast reaction with unreacted $U(I I I)$. We succeeded in preparing the first example of a terminal $U(V)$ terminal sulfide via metathesis of the $U(V)$ imido [K(2.2.2cryptand)][U(NAd) $\left.\left\{\mathrm{OSi}\left(\mathrm{O}^{\mathrm{t} B u}\right)_{3}\right\}_{4}\right], \quad \mathbf{1 8}^{27}$ (see the following chapter for the synthesis of imido complexes) with $\mathrm{H}_{2} \mathrm{~S}$ to give [K(2.2.2-cryptand)][US\{OSi $\left.\left.\left(\mathrm{O}^{\mathrm{t} B u}\right)_{3}\right\}_{4}\right], 19$ (Scheme 12). ${ }^{50}$ Based on DFT calculations, triple-bond character with a strong covalent interaction is suggested for the $\mathrm{UV}^{\mathrm{V}}=\mathrm{S}$ bond. The terminal $\mathrm{U}(\mathrm{V})$ sulfide rapidly reacts with $\mathrm{CS}_{2}$ to afford a terminal $\mathrm{U}(\mathrm{V})$ trithiocarbonate $[\mathrm{K}(2.2 .2$-cryptand $)]\left[\mathrm{U}\left(\mathrm{CS}_{3}\right)\left\{\mathrm{OSi}(\mathrm{OtBu})_{3}\right\}_{4}\right]$, $\mathbf{2 0}$ that was also obtained from the metathesis of $\mathbf{1 8}$ with $\mathrm{CS}_{2}$ probably via the highly reactive terminal $U(V)$ sulfide intermediate. 50
In contrast to the difficulty encountered in obtaining terminal sulfide complexes, the formation of a terminal $\mathrm{U}(\mathrm{V})$ monoxo

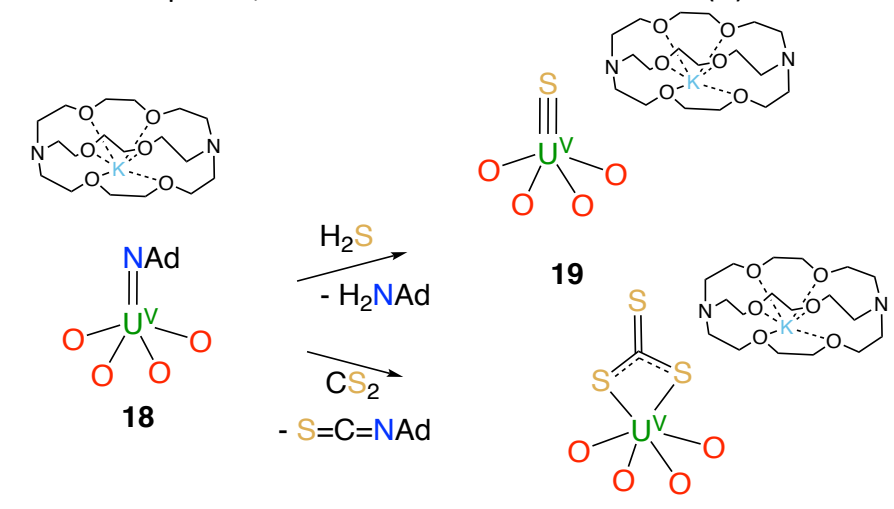

20

Scheme 12: Syntheses of the term na $U(V)$ su f de compex, 19 and of the $U(V)$ trithiocarbonate complex, 20.

complex is quite straightforward and can be achieved by reacting the bulky tetrasiloxide complex $\mathbf{2}$ with pyridine $\mathrm{N}$-oxide or even with $\mathrm{CO}_{2}$.

Several diuranium(IV) oxo-bridged have been reported, 5a, 33, 38, 51 but, surprisingly, the controlled synthesis of a diuranium(IV) bridging oxide revealed to be significantly more difficult than expected with tris-tertbutoxysiloxide as supporting ligand. Notably, the reaction of $\mathbf{4}$ with classical oxygen transfer agents such as PyNO, $\mathrm{Me}_{3} \mathrm{NO}$ or $\mathrm{N}_{2} \mathrm{O}$ only led to complicated mixtures of products including uranyl(VI) species. Only the use of the $\mathrm{N}_{2} \mathrm{O}$ adduct of the $\mathrm{N}$-heterocyclic carbene 1,3-dimesitylimidazol-2ylidene (IMes) IMes $\mathrm{N}_{2} \mathrm{O}^{52}$ in THF at $-80^{\circ} \mathrm{C}$ (Scheme 13) allowed the synthesis of the oxo-bridged diuranium(IV) complex $\left[\left\{\mathrm{U}\left(\mathrm{OSi}\left(\mathrm{O}^{\mathrm{t} B u}\right)_{3}\right)_{3}\right\}_{2}(\mu-\mathrm{O})\right], \mathbf{2 1}$, in $79 \%$ yield. ${ }^{53}$ The ability of the IMes $\mathrm{N}_{2} \mathrm{O}$ to selectively produce the oxodiuranium(IV) complex could be due to the higher reaction rates of this reagent ${ }^{54}$ compared to the other used oxygen transfer agents.<smiles>C[As](C)(O)O[Na]</smiles><smiles>O[Al]1(O)O[SiH2]O[Al]1(O)O[Al]1O[SiH2]O[SiH2]O1</smiles>

4

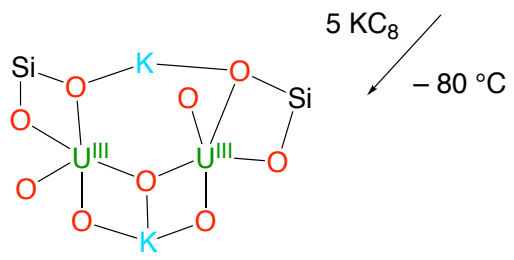

22

Scheme 13: Reaction of 4 with IMes $\mathrm{N}_{2} \mathrm{O}$ to afford the diuranium(IV) oxobridged complex 21 and is reduct on wh excess $K C_{8}$ to afford the diuranium(III) oxo-bridged complex 22. 
Oxo-bridged molecular complexes are attractive models for metal oxide catalysts but usually contain metal centres in high oxidation state. The unique example of a crystallographically characterized $\mathrm{U}(\mathrm{III})-\mathrm{O}-\mathrm{U}(\mathrm{III})$ complex ${ }^{55}$ was obtained from adventitious oxygen source during the reduction of a $U$ (III) complex. The reduction of the oxo-bridged diuranium(IV) complex, 21, leads to the multimetallic $\mathrm{U}(\mathrm{III})$ complex $\left[\mathrm{K}_{2}\left\{\left[\mathrm{U}\left(\mathrm{OSi}\left(\mathrm{O}^{\mathrm{t}} \mathrm{Bu}\right)_{3}\right)_{3}\right]_{2}(\mu-\mathrm{O})\right\}\right], \mathrm{K}_{2} \mathrm{U}-\mathrm{O}-\mathrm{U}, 22$. This result confirms the ability of the tertbutoxysiloxide ligand to stabilize multimetallic complexes of uranium in low oxidation states and provides a new precursor for studying the reactivity of dinuclear complexes of U(III) with small molecules.

\section{Reaction with organic azides}

The diuranium(III) complex $\mathbf{4}$ and the ion pair complex $\mathbf{3}$ show a different reactivity with organic azides (Scheme 14 and Scheme 15). Complex 4 reacts with adamantyl azide affording the $U(I V)$ complex $\left[\mathrm{U}\left(\mathrm{OSi}\left(\mathrm{O}^{\mathrm{t} B u}\right)_{3}\right)_{4}\right], 1$, and a dinuclear bis-imido complex of uranium( $(\mathrm{VI}) \quad\left[\mathrm{U}_{2}(\mathrm{NAd})_{4}\left(\mathrm{OSi}\left(\mathrm{O}^{t} \mathrm{Bu}\right)_{3}\right)_{4}\right]$, 26. The bis-imido complex presents a cation-cation interaction ${ }^{56}(\mathrm{CCl})$ between two $\left[\mathrm{U}(\mathrm{NAd})_{2}\right]^{2+}$ units with a U-N-U angle of $108.4(5)^{\circ}$ and a nonplanar arrangement of the two imido groups. Both $\left[\mathrm{U}(\mathrm{NAd})_{2}\right]^{2+}$ motifs are nearly linear and can be seen as nitrogen analogues

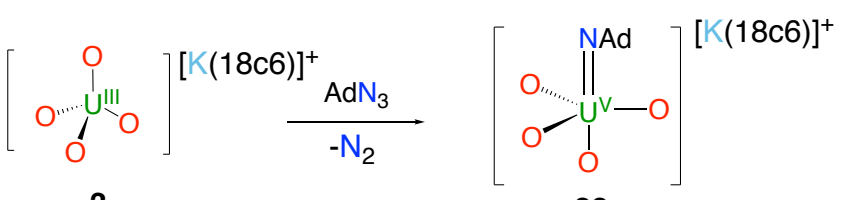

3 23

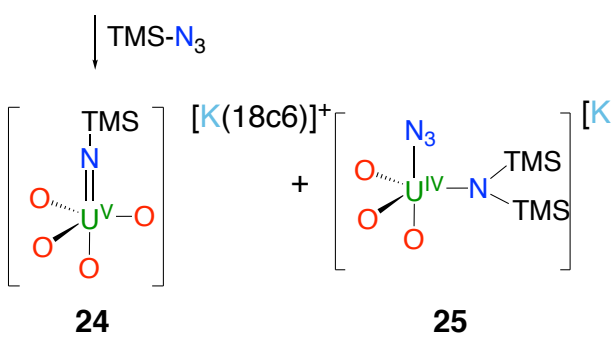
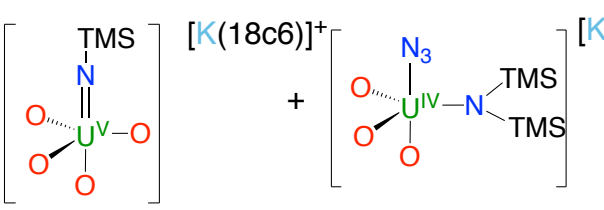

Scheme 14: React on of the uran um( I comp ex, 3 with organic azides.

of the $\mathrm{UO}_{2}{ }^{2+}$ moiety. The dinuclear complex $\mathbf{2 6}$ provided the first example of a uranium(VI) trans-bisimido complex showing a cation-cation interaction between the two imido groups.

Examples of dinuclear bis-imido complexes are rare in uranium chemistry 57 and they all present a diamond-shaped geometry. The reaction is likely to proceed with the formation of a $U(V)$ azide that then disproportionates to $\mathrm{U}(\mathrm{VI})$ and $\mathrm{U}(\mathrm{IV})$ accompanied by ligand scrambling.

The bulky environment provided by the four siloxides in complex 3 prevents disproportionation during the reaction with the bulky adamantyl azide affording a stable $\mathrm{U}(\mathrm{V})$ terminal imido complex. Less bulky amides such as TMS-azide failed to stabilize the $U(V)$ complex. Probably the bulky environment provided by the siloxide ligands and the adamantyl substituents are key in preventing $\mathrm{U}(\mathrm{V})$ disproportionation. The tendency of $\mathrm{U}(\mathrm{V})$ imido complexes to undergo disproportionation, even if to a less extent that uranyl(V) compounds, 58 is probably the reason of the limited number of isolated compounds reported in the

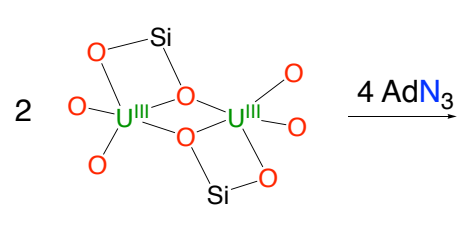

4

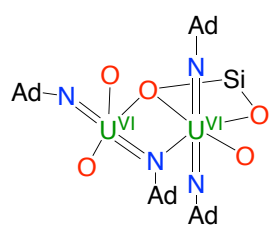

26
Scheme 15: React on of the nevira uran um ( ) comp ex, 4 with adamantyl azide. literature. ${ }^{37 g}$ However, such complexes may provide desirable precursors for reactivity studies or synthesis of otherwise non accessible compounds such as the terminal U(V) sulfide 19.

\section{Reaction with metal azides: synthesis of uranium nitrides}

In view of the high reactivity of the $\mathrm{U}$ (III) siloxide complexes with heteroallenes, we became interested in investigating their reactivity with the isoelectronic azide $\left(\mathrm{N}_{3}{ }^{-}\right)$as a possible route to uranium nitride complexes. Metal azides are, indeed, known as versatile precursors for the obtention of nitride complexes. Uranium nitrides are of great fundamental interest for investigating multiple $\mathrm{M}$-Ligand bonding $37 \mathrm{~b}, 59$ and nitride transfer reactivity. The synthesis and study of molecular nitride complexes is also attractive because of the importance of UN materials as potential alternative nuclear fuel. 59b, 60 Moreover, we were particularly interested by the high activity of UN materials reported by Haber in the catalytic conversion of $\mathrm{N}_{2}$ and $\mathrm{H}_{2}$ to $\mathrm{NH}_{3}{ }^{7}$ The first examples of uranium nitrides were

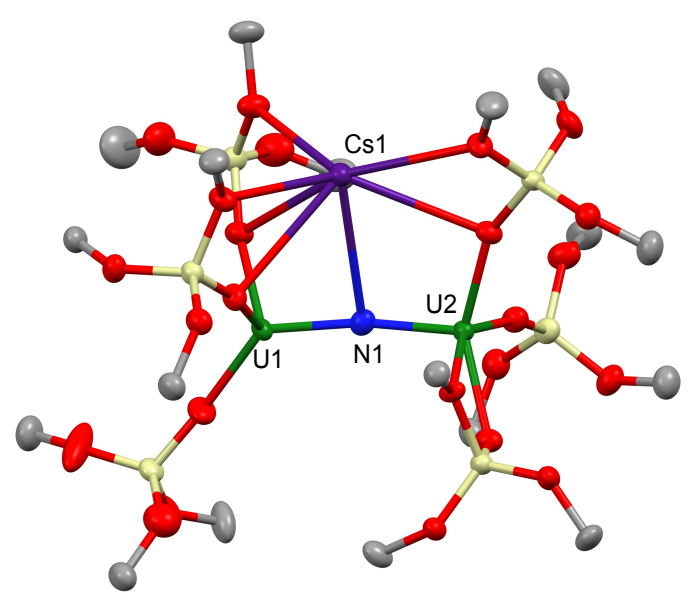

Figure 4: Molecular structure of 29 , probab it at $50 \%$, hydrogen atoms and methv groups are om tled for cartv

obtained by Evans and then by our group from the reaction of $\mathrm{U}$ (III) complexes with metal azides, but led to multimetallic (3-8 uranium atoms) clusters containing both bridging nitrides and bridging azide ligands. ${ }^{61} \mathrm{~A}$ series of stable nitride bridged diuranium,(U(IV)/U(IV); $\quad \mathrm{U}(\mathrm{V}) / \mathrm{U}(\mathrm{IV}) ; \quad \mathrm{U}(\mathrm{V}) / \mathrm{U}(\mathrm{V}))$ complexes containing a linear $\mathrm{U}=\mathrm{N}=\mathrm{U}$ motif were subsequently reported by Cummins and coworkers. The parent diuranium(IV) complex was prepared from the reaction of a U(III) tris-amide species with unprotected azide and then stepwise oxidized. ${ }^{62}$ Only a 
handful of additional examples of dinuclear and terminal nitrides have been reported to this date from the reaction of $\mathrm{U}$ (III) with azides, suggesting that the choice of reaction conditions and supporting ligands is critical in the isolation of stable uranium nitrides. $27,37 \mathrm{~b}, 59 \mathrm{~b}, 63$

We found that only the dinuclear complex 4 would react in a controlled manner with metal azides to afford a nitride compound in high yield. In contrast, the reaction of the bulky tetra-siloxide complex $\mathbf{3}$ with cesium azide led to the formation

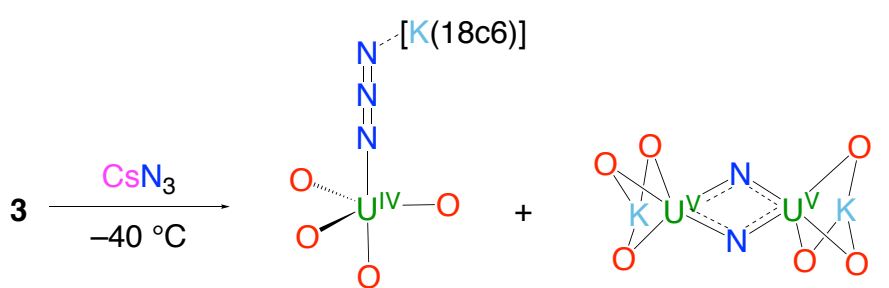

27

Scheme 16: Reaction of the ion-paired uranium(III) complex, 3 with cesium azide.

of multiple products from which we could isolate only a few crystals of the $\mathrm{U}(\mathrm{IV})$ azido complex $\left[\mathrm{K}(18 \mathrm{c} 6) \mathrm{U}\left(\mathrm{N}_{3}\right)\left(\mathrm{OSi}\left(\mathrm{O}^{\mathrm{t}} \mathrm{Bu}\right)_{3}\right)_{4}\right]$, 27 and of the di $\mu$-nitride diuranium(V) complex [KU( $\mu$ $\left.\mathrm{N})\left(\mathrm{OSi}\left(\mathrm{O}^{\mathrm{t} B u}\right)_{3}\right)\right]_{2} \mathbf{2 8 .} .^{27}$ (Scheme 16).

If a synthetic route to the terminal azide complex could be identified it could provide access to a terminal nitride complex. The most interesting features in the structure of $\mathbf{2 8}$ is the presence of two nitride atoms bridging two $\mathrm{U}(\mathrm{V})$ centres in a diamond-shaped geometry. Complex $\mathbf{2 8}$ is the first example of a $\mathrm{U}_{2} \mathrm{~N}_{2}$ core isolated from the reaction of $\mathrm{U}(\mathrm{III})$ with azides. The formation of this unprecedented $U(V) / U(V)$ complex may involve a highly reactive $U(V)$ terminal nitride intermediate that affords the bis(nitride) complex trough the loss of one siloxide ligand. The crowded environment and the high complex charge

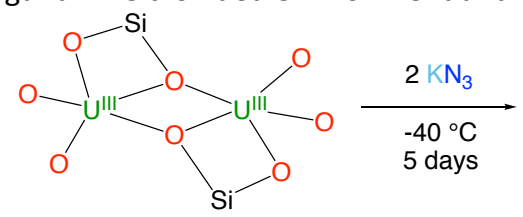

4<smiles>N#[W]c1ccccc1</smiles><smiles>ON1[Al]2(O)O[Al](O)O[Si]1(O)O2</smiles>

29

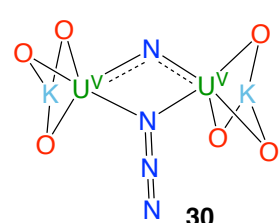

30 $70^{\circ} \mathrm{C}$
$24 \mathrm{~h}$

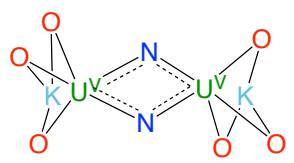

28
Scheme 17: Reaction of $4 w$ th a $k$ az des to afford the $n$ tr de-bridged complex 29 and the duran um( $V)$ n tr de-azide-bridged complex 30. Thermolysis of $\mathbf{3 0}$ to afford the diuranium(V) bis(nitride)-bridged complex 28.

result in a low stability of the putative terminal nitride intermediate and in the impossibility to trap it. This is in line with the high reactivity demonstrated by the elusive uranium nitride intermediate $\left[\mathrm{UN}\left\{\mathrm{N}\left(\mathrm{SiMe}_{3}\right)_{2}\right\}\left(\mathrm{C}_{5} \mathrm{Me}_{5}\right)_{2}\right]$ which engages in intramolecular $\mathrm{C}-\mathrm{H}$ bond activation ${ }^{64}$ and by the isolated terminal $U(\mathrm{~V})$ nitride. ${ }^{37 \mathrm{~b}}$

The reaction of the dinuclear tris-siloxide complex 4 with $\mathrm{CsN}_{3}$ (Scheme 17) affords the nitride bridged diuranium(IV) complex $\left[\mathrm{Cs}(\mu-\mathrm{N})\left\{\mathrm{U}\left(\mathrm{OSi}\left(\mathrm{O}^{\mathrm{t} B u}\right)_{3}\right)_{3}\right\}_{2}\right], 29$ in $47 \%$ yield. ${ }^{27}$ The reaction is likely to proceed via the formation of an azide-bridged complex that eliminate dinitrogen to afford the final nitride. The solidstate structure of $\mathbf{2 9}$ (Figure 4) consists of a heterotrinuclear $(\mathrm{U}, \mathrm{U}, \mathrm{Cs})$ complex where two $\mathrm{U}(\mathrm{IV})$ cations are held together by a bridging nitride $\mathrm{N}^{3-}$ ligand in a nearly linear fashion (U-N-U angle : $\left.170.2(3)^{\circ}\right)$ with short U-N nitride bond distances (U1-N1 2.058(5) $\AA$, U2-N1 2.079(5) $\AA$ ) in agreement with the presence of a multiple $\mathrm{U}=\mathrm{N}$ bond.

These values are similar to those found in other nitride-bridged

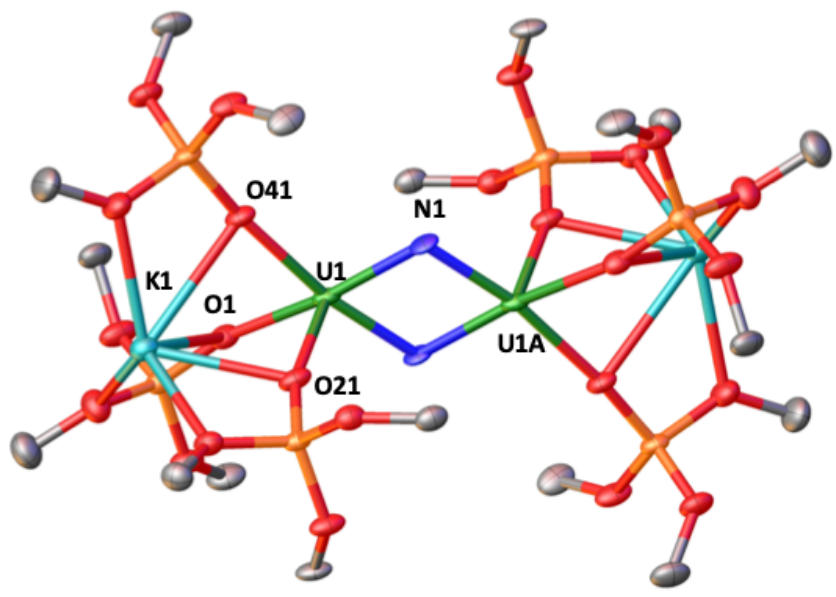

Figure 5: Molecular structure of 28; probability at 50\%; hydrogen atoms and methr groups are om tled for cartv seected bond dstances $|\dot{A}|$ U1-N1, 2.022(5); U1-O ${ }_{\text {avg, } 2.23(3)}$

diuranium(IV) complexes presenting a linear $\mathrm{U}=\mathrm{N}=\mathrm{U}$ fragment $(\mathrm{U}=\mathrm{N}$ distance ranging from 2.05 to $2.09 \AA$ and $\mathrm{U}-\mathrm{N}-\mathrm{U}$ angle ranging from 159 to $\left.175^{\circ}\right) .61 \mathrm{~b}, 62,63 \mathrm{~b}, 63 \mathrm{~h}, 65$ An important structural feature of the complex 29 compared to the other linear nitride-bridged $U(I V) / U(I V)$ complexes is its heteropolymetallic neutral nature. Notably, in 29 the six siloxides act as multidentate bridging ligands binding the $\mathrm{Cs}^{+}$ cation through 6 tert-butoxy oxygen atoms. The $\mathrm{Cs}^{+}$cation lies at the apical position of the nitride ligand and remains bound in a solution of toluene or THF as indicated by the fact that a different species is obtained upon addition of cryptand to a solution of 29.

The bis-nitride bridged diuranium(V) complex can be prepared in $53 \%$ yield from the reaction of 4 with 2 equivs of potassium azide followed by heating at $70^{\circ} \mathrm{C}$. These diuranium complexes provide a good substrate for comparative studies of the reactivity of bridging nitrides for different oxidation states of uranium. The $X$ Ray crystals structure of complex $\mathbf{2 8}$ is presented in Figure 5.

Surprisingly all nitride complexes reported up to 2016 contained uranium in high oxidation state $(\mathrm{U}(\mathrm{IV}), \mathrm{U}(\mathrm{V}), \mathrm{U}(\mathrm{VI})$, in spite of the 


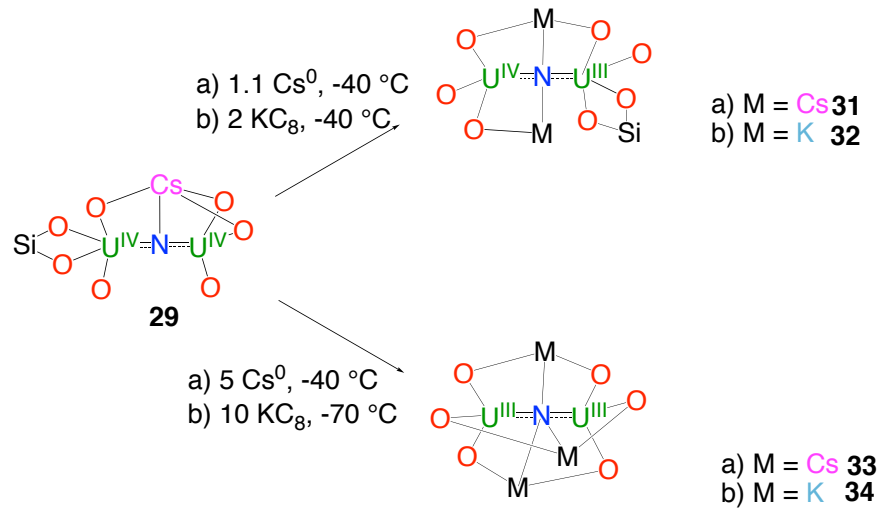

Scheme 18: Syntheses of the $U(U) \cup(V)$ br dg $n g n t r d e$, and of the $U($ ) U ( ) bragng ntrde wencesum and potass um catons

fact that one of the global objectives behind the synthesis of these species was to model the properties of $\mathrm{U}(\mathrm{III}) \mathrm{N}$ material. In our group, we investigated the reduction of diuranium(IV) complex 29 with different reducing agents. Stepwise reduction of 29 with 1 equiv or a large excess of $\mathrm{Cs}^{0}$ in THF at $-40^{\circ} \mathrm{C}$ and under argon afforded the $\mathrm{U}(\mathrm{III}) / \mathrm{U}(\mathrm{IV})$ complex $\mathrm{Cs}_{2}\{(\mu-$ $\left.\mathrm{N})\left[\mathrm{U}\left(\mathrm{OSi}\left(\mathrm{O}^{t} \mathrm{Bu}\right)_{3}\right)_{3}\right]_{2}\right\}, 31$ and the $\mathrm{U}(\mathrm{III}) / \mathrm{U}(\mathrm{III})$ complex $\mathrm{Cs}_{3}\{(\mu-$ $\left.\mathrm{N})\left[\mathrm{U}\left(\mathrm{OSi}\left(\mathrm{O}^{\mathrm{t}} \mathrm{Bu}\right)_{3}\right)_{3}\right]_{2}\right\}, 33$, respectively (Scheme 18). ${ }^{63 \mathrm{f}}$

When the diuranium(IV) nitride complex 29 is reacted with excess $\mathrm{KC}_{8}$ (10 equivs) in THF at $-70^{\circ} \mathrm{C}$, the potassium analogue $\left[\mathrm{K}_{3}\left\{\left[\mathrm{U}\left(\mathrm{OSi}\left(\mathrm{O}^{\mathrm{t}} \mathrm{Bu}\right)_{3}\right)_{3}\right]_{2}(\mu-\mathrm{N})\right\}\right], \mathbf{3 4}$, was isolated in $70 \%$ yield. ${ }^{19 d}$

The nature of the cation bound to the $\mathrm{U}$ (III) complexes has a strong impact on their solution and solid-state stability. The cesium analogue is stable only few hours even at low temperature rendering more difficult the study of its reactivity. The solid-state structure of the $U($ III)/U(IV) and $U(I I I) / U(I I I)$ nitrides presents respectively two and three cations bound in the pockets formed by the siloxide ligands (the X-Ray crystal structure of complex $\mathbf{3 4}$ is presented in Figure 6). The cations

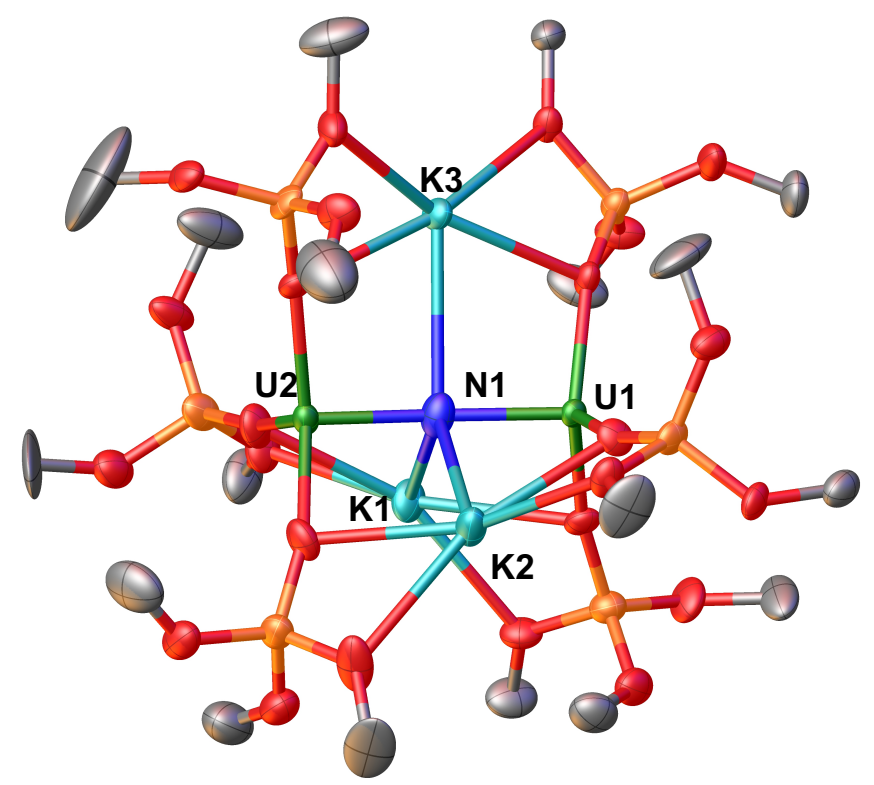

Figure 6: Molecular structure of 34, probab iv at $50 \%$, hvdrogen atoms and methy groups are om tred for $c$ arty also bind the nitride group in a linear (31) or triangular fashion (33, 34). In the $U(I I I) / U(I I I)$ complexes the strong binding of the cation $\left(\mathrm{K}^{+}\right.$or $\left.\mathrm{Cs}^{+}\right)$creates a flexible metallo-ligand framework that holds together the two uranium centres in close proximity. The cations could not be removed by addition of cryptand, showing that they are tightly bound. In all these $\mathrm{U}$ (III) containing complexes, the values of the U-N distances in the $\mathrm{Cs}_{2} \mathrm{U}^{\prime \prime \prime} \mathrm{NU}^{\prime \mathrm{V}}$, $\mathrm{CS}_{3} \mathrm{U}^{\prime \prime \prime} \mathrm{NU} U^{\prime \prime \prime}$, and $\mathrm{K}_{3} \mathrm{U}^{\prime \prime \prime} \mathrm{NU}$ "II complexes (Table 1 ) and the linear arrangement of the UNU core suggest the presence of U'II-N multiple bonding. The variation in the $\mathrm{U}=\mathrm{N}$ bond lengths with variation of the oxidation state in the $\mathrm{Cs}_{\mathrm{x}} \mathrm{UNU}$ cores is larger than what observed in linear U'vNU'v and UvNUv cores supported by bulky amides. This larger difference is most likely due to the presence of a different number of bound cations in the siloxide complexes leading to a reduced electron density in the UNU core.

More recently, computational studies showed a marked covalent character of the $\mathrm{K}_{3} \mathrm{U}^{\prime \prime \prime} \mathrm{NU}$ "II with a U-N bond order of 1.4. ${ }^{66}$ Moreover, magnetic data measured for $\mathrm{K}_{3} \mathrm{U}^{\prime \prime \prime} \mathrm{NU} \mathrm{U}^{\prime \prime \prime}$ at variable temperature show a maximum at $23 \mathrm{~K}$ in the $\chi$ versus $T$ plot showing that the two uranium centres are antiferromagnetically coupled at low temperature. These results indicate that nitride ligands can promote magnetic communication between $\mathrm{U}(\mathrm{III})$ centres.

\begin{tabular}{|l|l|l|l|l|}
\hline & $\mathrm{Cs} U N \mathrm{~N}, \mathbf{2 9}$ & $\mathrm{CS}_{2} \mathrm{UNU}, 31$ & $\mathrm{CS}_{3} \mathrm{UNU}, 33$ & $\mathrm{~K}_{3} \mathrm{UNU}, \mathbf{3 4}$ \\
\hline $\mathrm{U} 1-\mathrm{N}$ & $2.058(5) \AA$ & $2.099(12) \AA$ & $2.1495(12) \AA$ & $2.129(14) \AA$ \\
\hline $\mathrm{U} 2-\mathrm{N}$ & $2.079(5) \AA$ & $2.243(25) \AA$ & $2.1495(12) \AA$ & $2.111(14) \AA$ \\
\hline $\mathrm{U}-\mathrm{O}_{\text {avg }}$ & $2.19(3) \AA$ & $2.243(25) \AA$ & $2.282(24) \AA$ & $2.303(7) \AA$ \\
\hline $\mathrm{M} 1-\mathrm{N}$ & $3.393(4) \AA$ & $3.276(12) \AA$ & $3.348(8) \AA$ & $3.115(7) \AA$ \\
\hline $\mathrm{M} 2-\mathrm{N}$ & - & $3.635(12) \AA$ & $3.348(8) \AA$ & $3.017(16) \AA$ \\
\hline $\mathrm{M} 3-\mathrm{N}$ & - & - & $3.22(2)$ & $3.243(15) \AA$ \\
\hline $\mathrm{U}-\mathrm{N}-\mathrm{U}$ & $170.2(3)^{\circ}$ & $169.1(7)^{\circ}$ & $174.2(11)^{\circ}$ & $173.7(7)^{\circ}$ \\
\hline
\end{tabular}

Table 1: Comparative structural parameters of complexes $29,31,33$, and 34 


\section{Reactivity of siloxide-supported bridged complexes}

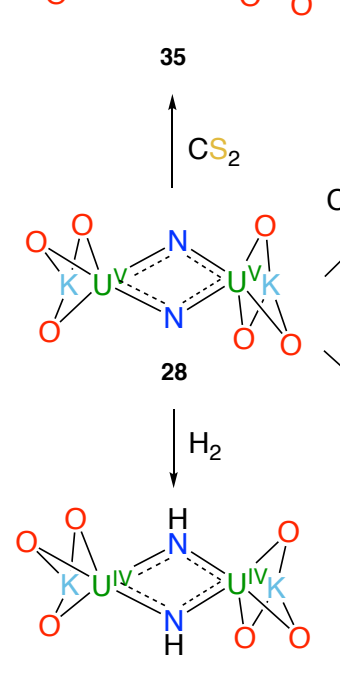

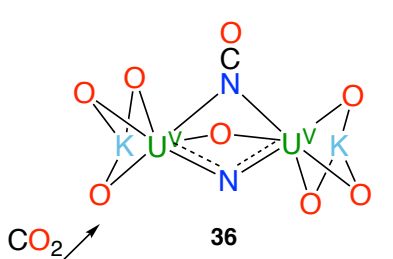

38

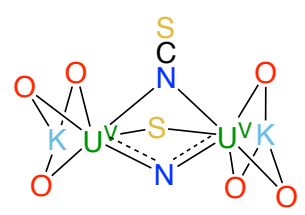

nitride

the cyanide acts as a two-electron reducing agent while inserting into the nitride to yield a U'V $\mathrm{N}=\mathrm{C}=\mathrm{NU}^{\prime \mathrm{IV}}$ species. ${ }^{62}$ The same complex was reported not to react with carbon monoxide. In contrast, the terminal uranium( $\mathrm{V})$ nitride $\left[\mathrm{U}(\right.$ TrenTIPS) $(\mathrm{N})]\left[\mathrm{Na}(12 \mathrm{C} 4)_{2}\right] \quad\left(\right.$ TrenTIPS $\left.=\mathrm{N}\left(\mathrm{CH}_{2} \mathrm{CH}_{2} \mathrm{NSi}^{\mathrm{i} P P_{3}}\right)_{3}\right)$ effects the two electron oxidation of $\mathrm{CO}$ to afford cyanate via attack of the nucleophilic nitride to the antibonding orbitals of CO. ${ }^{63 e}$ These contrasting results seemed to point to a reduced reactivity of uranium bound bridging nitrides and incited us to explore the reactivity of siloxide supported nitride bridged complexes.

\section{Reactivity of uranium(V) nitride bridged complexes}

The diuranium(V) bis(nitride) $\mathbf{2 8}$ demonstrated high nucleophilic reactivity towards diverse small molecules which is summarized in Scheme $19 .{ }^{53}$ The reactivity of a toluene solution of $\mathbf{2 8}$ with one equiv of $\mathrm{CS}_{2}$ led to $\mathrm{CS}_{2}$ cleavage affording the sulfide-thiocyanate complex $\left[\mathrm{K}_{2}\left\{\left[\mathrm{U}\left(\mathrm{OSi}\left(\mathrm{O}^{\mathrm{t} B u}\right)_{3}\right)_{3}\right]_{2}(\mu-\mathrm{N})(\mu-\mathrm{S})(\mu-\right.\right.$ $\mathrm{NCS})\}]$, 35. Cleavage of $\mathrm{CS}_{2}$ and concomitant formation of NCS was also observed for the $\mathrm{U}(\mathrm{IV})$ bridging nitride 29 (see next section) and for $\mathrm{U}(\mathrm{V})$ and $\mathrm{U}(\mathrm{VI})$ terminal nitrides. ${ }^{74}$ In none of these cases, though, a uranium sulfide could be isolated. For complex 29 and the $U(V)$ terminal nitride $\left[\mathrm{NU}\left(\operatorname{Tren}^{\mathrm{TIPS}}\right)\right]\left[\mathrm{K}(\mathrm{B} 15 \mathrm{C} 5)_{2}\right]$ a putative uranium sulfide further reacts with $\mathrm{CS}_{2}$ to give a trithiocarbonate ligand. ${ }^{74}$ The different reactivity of $\mathbf{2 8}$ could be explained in terms of higher steric

Scheme 19: React vev of the d uran um( $V$ ) b s-nitride complex 28 with $\mathrm{CS}_{2}, \mathrm{CO}_{2}$ $\mathrm{CO}$ and $\mathrm{H}_{2}$.

The study of the reactivity of metal nitrides is of high relevance for the future development of catalytic processes directed to build organic molecules with added value such as amino acids, pharmaceuticals or agrochemicals 67 from cheap raw material such as $\mathrm{N}_{2}, \mathrm{CO}_{2}, \mathrm{CO}$. N-C bond formation reactions are particularly important in this context. 68 Metal nitrides are important intermediates in the biological and industrial conversion of $\mathrm{N}_{2}$ to ammonia and $\mathrm{N}-\mathrm{H}$ formation is a crucial step in both processes. In this context, a wide range of studies has been directed to the development of metal complexes able to effect dinitrogen transformation in mild conditions. ${ }^{69}$ Particularly desirable would be the use of cheap and/or largely available molecules such as $\mathrm{H}_{2}, \mathrm{CO}$ or $\mathrm{CO}_{2}$ in combination with dinitrogen for the synthesis of ammines and new organic products. However, examples of direct dinitrogen cleavage by $\mathrm{H}_{2}, \mathrm{CO}$ or $\mathrm{CO}_{2}$ are extremely rare ${ }^{70}$.

Examples of $\mathrm{N}-\mathrm{C}$ bond formation from the reaction of carbon dioxide ${ }^{71 a}$, 71b $\left\{\right.$ Brask, $2002 \# 22948,71$ c, 71d or carbon monoxide ${ }^{63 e}, 72$ with activated nitride complexes of transition metals or hydrogenolysis by d-block metal nitride are also extremely rare. $69 \mathrm{a}, 72 \mathrm{a}, 73$

These reactions may involve electron transfer from the metal to the substrate or just the functionalization of the highly nucleophilic nitride group.

Very little is known of the reactivity of uranium nitrides in spite of their relevance in nuclear industry ${ }^{60}$ and their activity as catalysts $2 a, 7$ in the Haber process. Prior to studies from our group of the reactivity of uranium nitrides, a seminal study from the Cummins group of the reactivity of the $\mathrm{U}^{v} \mathrm{NU}^{\mathrm{v}}$ core supported by bulky amides fragment with $\mathrm{NaCN}$ showed that hindrance around the sulfide. In contrast, the $\mathrm{U}(\mathrm{VI})$ terminal nitride [NU(Tren $\left.{ }^{\text {TIPS }}\right)$ ] cleaves $\mathrm{CS}_{2}$ affording a $\mathrm{U}(\mathrm{IV})$ terminal thiocyanate and elemental sulfur. ${ }^{74}$ The reaction of a toluene solution of complex 28 with 1 equiv of $\mathrm{CO}_{2}$ led to $\mathrm{C}-\mathrm{O}$ cleavage resulting in the isolation of the oxo-cyanate-complex $\left[\mathrm{K}_{2}\left\{\left[\mathrm{U}\left(\mathrm{OSi}\left(\mathrm{O}^{\mathrm{t}} \mathrm{Bu}\right)_{3}\right)_{3}\right]_{2}(\mu-\mathrm{N})(\mu-\mathrm{O})(\mu-\mathrm{NCO})\right\}\right]$, 36. A similar reactivity leading to oxo and cyanate ligands is also observed for the $U(V)$ and the $U(V I)$ terminal nitrides $\left[\mathrm{NU}\left(\operatorname{Tren}^{\mathrm{TIPS}}\right)\right]\left[\mathrm{K}(\mathrm{B} 15 \mathrm{C} 5)_{2}\right]$ and $\left[\mathrm{NU}\left(\right.\right.$ Tren $\left.\left.^{\mathrm{TIPS}}\right)\right] .{ }^{74}$ 
The reaction of $\mathbf{2 8}$ with 2 equivs of $\mathrm{CO}$ at room temperature affords the complex $\left[\mathrm{K}_{2}\left\{\left[\mathrm{U}\left(\mathrm{OSi}\left(\mathrm{O}^{\mathrm{t} B u}\right)_{3}\right)_{3}\right]_{2}(\mu-\mathrm{NC})(\mu-\mathrm{O})(\mu-\mathrm{NCO})\right\}\right]$, 37. Two equivs of $\mathrm{CO}$ react with the two bridging nitride ligands with different outcomes. In fact, one nitride cleaves the CO triple bond affording a cyanido and an oxo complex, while the second nitride undergoes reductive carbonylation to form a cyanate ligand with the concomitant reduction of the two $U$ centres from $U(V)$ to $U(I V)$. Thus, both ligand-based and metalbased reactivity are observed. The formation of thiocyanate, cyanate, and cyanide was confirmed by structural studies and ${ }^{13} \mathrm{C} \mathrm{NMR}$ analysis of the products after reaction with ${ }^{13} \mathrm{CS}_{2},{ }^{13} \mathrm{CO}_{2}$ and ${ }^{13} \mathrm{CO} .{ }^{53}$

The complete cleavage of the CO triple bond (one of the strongest bonds in nature) in ambient conditions is particularly remarkable and is probably the result of the cooperative binding of $\mathrm{CO}$ by the two metal centres. Notably, CO cleavage is not observed in the reaction of terminal nitrides with $\mathrm{CO}$ which leads to reductive carbonylation. ${ }^{74}$ Complete CO cleavage is a key step in the Fischer-Tropsch hydrocarbon production from $\mathrm{CO}$ and $\mathrm{H}_{2}$ but examples of complete cleavage of $\mathrm{CO}$ by molecular complexes remain rare. ${ }^{75}$

The reactivity of complex 28 with 1 atm of $\mathrm{H}_{2}$ in ambient conditions is remarkable in that the bis-nitride effects the oxidative cleavage of $\mathrm{H}_{2}$ in mild conditions to yield the bis-imido complex $\left[\mathrm{KU}(\mu-\mathrm{NH})\left(\mathrm{OSi}\left(\mathrm{O}^{\mathrm{t}} \mathrm{Bu}\right)_{3}\right)\right]_{2}, 38 .^{53}$ Notably, cleavage of $\mathrm{H}_{2}$ by metal-nitride is a rarely observed event.

The reaction pathway probably does not involve $\mathrm{H}_{2}$ coordination to the metal centre but direct attack of $\mathrm{H}_{2}$ to the two nucleophilic nitrides as previously reported for a terminal iridium complex. ${ }^{76}$ The reactivity of complex $\mathbf{2 8}$ with $\mathrm{H}_{2}$ is a likely model of the intermediates formed during the conversion of $\mathrm{N}_{2}$ and $\mathrm{H}_{2}$ into ammonia promoted by uranium nitrides in the Haber-Bosch process.

\section{Reactivity of uranium(IV) nitride bridged complexes}

The overnight thermolysis of 29 at $80^{\circ} \mathrm{C}$ in toluene solution resulted in the complete transformation of $\mathbf{2 9}$ to afford the new imido bridged siloxide/silandiolate diuranium(IV) complex $\mathrm{Cs}\left\{\left(\mu-\mathrm{N}^{\mathrm{t} B u}\right)\left(\mu-\mathrm{O}_{2} \mathrm{Si}\left(\mathrm{O}^{\mathrm{t}} \mathrm{Bu}\right)_{2}\right) \mathrm{U}_{2}\left(\mathrm{OSi}\left(\mathrm{O}^{\mathrm{t}} \mathrm{Bu}\right)_{3}\right)_{5}\right\}$, 39. The thermolysis reaction leads to cleavage of a $\mathrm{C}-\mathrm{O}$ bond of one siloxide ligand and to tert-butyl group transfer to the bridging nitride resulting in the formation of a new $\mathrm{N}-\mathrm{C}$ bond. This reactivity demonstrated the strong nucleophilic character of the bridging nitride in $\mathbf{2 9}$ and incited to explore the reactivity with small molecules summarized in Scheme 20.

We found that the bridging nitride in the $\mathrm{U}(\mathrm{IV}) / \mathrm{U}(\mathrm{IV})$ complex 29 acts as a strong nucleophile towards $\mathrm{CS}_{2}, \mathrm{CO}_{2}{ }^{77}$ and $\mathrm{CO}^{77}$ leading to $\mathrm{C}-\mathrm{S}$ or $\mathrm{C}-\mathrm{O}$ cleavage and $\mathrm{N}-\mathrm{C}$ bond formation yielding respectively the thiocyanate/trithiocarbonate complex $\operatorname{Cs}\{(\mu-$ $\left.\mathrm{NCS})\left(\mu-\mathrm{CS}_{3}\right)\left[\mathrm{U}\left(\mathrm{OSi}\left(\mathrm{O}^{\mathrm{t} B u}\right)_{3}\right)_{3}\right]_{2}\right\},(43)$, the oxo/cyanate complex $\mathrm{Cs}\left\{(\mu-\mathrm{NCO})(\mu-\mathrm{O})\left[\mathrm{U}\left(\mathrm{OSi}\left(\mathrm{O}^{\mathrm{t}} \mathrm{Bu}\right)_{3}\right)_{3}\right]_{2}\right\},(44)$, and the oxo/cyanide complex $\mathrm{Cs}\left[\left\{\mathrm{U}\left(\mathrm{OSi}(\mathrm{OtBu})_{3}\right)_{3}\right\}_{2}(\mu-\mathrm{CN})(\mu-\mathrm{O})\right]$, (41) respectively. The high nucleophilic character of the $U(I V) / U(I V)$ nitride leads to complete cleavage of the CO triple bond as observed for the

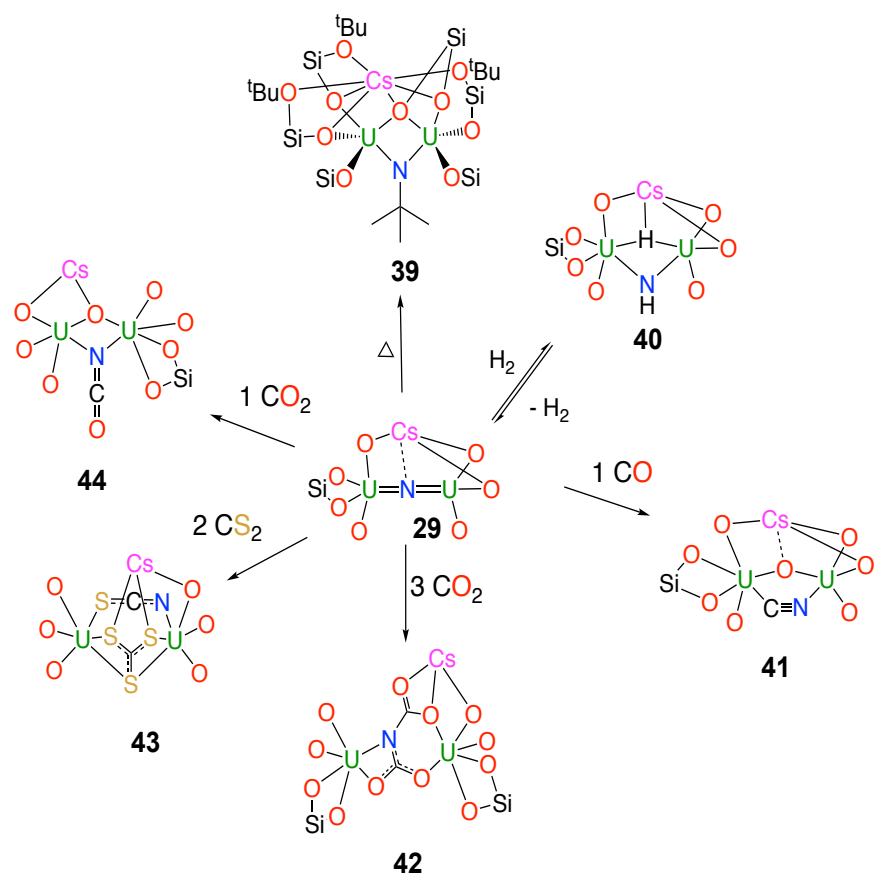

Scheme 20: Thermolysis and reactivity with $\mathrm{CS}_{2}, \mathrm{CO}_{2}, \mathrm{CO}$ and $\mathrm{H}_{2}$ of the duranum( V) brdg ng nerde, compex 29.

bis-nitride $\mathbf{2 8}$. The cyanide in $\mathbf{4 1}$ is easily alkylated by MeOTf to afford MeCN.

Addition of excess (more than 3 equivs) $\mathrm{CO}_{2}$ to $\mathbf{2 9}$ led to the unprecedented electrophilic addition of $2 \mathrm{CO}_{2}$ molecules to the bridging nitride affording the bis-carbamate complex $\operatorname{Cs}\{(\mu$ $\left.\left.\mathrm{NC}_{2} \mathrm{O}_{4}\right)\left[\mathrm{U}\left(\mathrm{OSi}\left(\mathrm{O}^{\mathrm{t} B u}\right)_{3}\right)_{3}\right]_{2}\right\},(\mathbf{4 2})$. The $\mathrm{CsUNU}$ core behaves as a Frustrated Lewis Pair and such reactivity encouraged to explore its ability to cleave $\mathrm{H}_{2}$. In spite of their relevance in biological and industrial dinitrogen reduction the formation of imidohydrido species from $\mathrm{H}_{2}$ addition to metal-nitrides or metaldinitrogen complexes remains extremely rare. ${ }^{78}$ The bifunctional Lewis acid-Lewis base character of complex 29, led to the reversible heterolytic cleavage of dihydrogen under ambient conditions to afford the reversible formation of the parent imide-hydride complex $\left[\mathrm{Cs}\left\{\mathrm{U}\left(\mathrm{OSi}\left(\mathrm{O}^{\mathrm{t} B u}\right)_{3}\right)_{3}\right\}_{2}(\mu-\mathrm{H})(\mu-\right.$ $\mathrm{NH})$ ], 40.79 This complex can transfer the hydride to acetonitrile and $\mathrm{CO}_{2}$ to afford azavinylidene and formate insertion products respectively.

\section{Reactivity of nitride bridged diuranium(III) complexes}

The reaction between $\mathrm{Cs}_{3}\left\{(\mu-\mathrm{N})\left[\mathrm{U}\left(\mathrm{OSi}\left(\mathrm{O}^{t} \mathrm{Bu}\right)_{3}\right)_{3}\right]_{2}\right\}, 33$ and 1 equiv of ${ }^{13} \mathrm{CS}_{2}$ led to the formation of the complex $\left[(\mathrm{Cs}(\mathrm{THF}))_{2}\left\{\left[\mathrm{U}\left(\mathrm{OSi}\left(\mathrm{O}^{\mathrm{t} B u}\right)_{3}\right)_{3}\right]_{2}(\mu-\mathrm{S})_{2}\right\}\right], \quad \mathbf{4 5}^{63 \mathrm{f}}$ and of $\mathrm{N}^{13} \mathrm{CS}^{-}$ suggesting that the transfer of the nitride ligand and the concomitant cleavage of a $\mathrm{C}=\mathrm{S}$ double bond occurred. The oxidation of the $U$ ions from $U(I I I)$ to $U(I V)$ indicates that metalbased reactivity has also occurred and that other unidentified species must be formed.

More remarkable is the ability of complex $\mathrm{Cs}_{3}\{(\mu-$ $\left.\mathrm{N})\left[\mathrm{U}\left(\mathrm{OSi}\left(\mathrm{O}^{\mathrm{t}} \mathrm{Bu}\right)_{3}\right)_{3}\right]_{2}\right\}, 33$ to react with dinitrogen in ambient conditions. The concomitant formation of decomposition products, though, prevented the successful isolation of the 


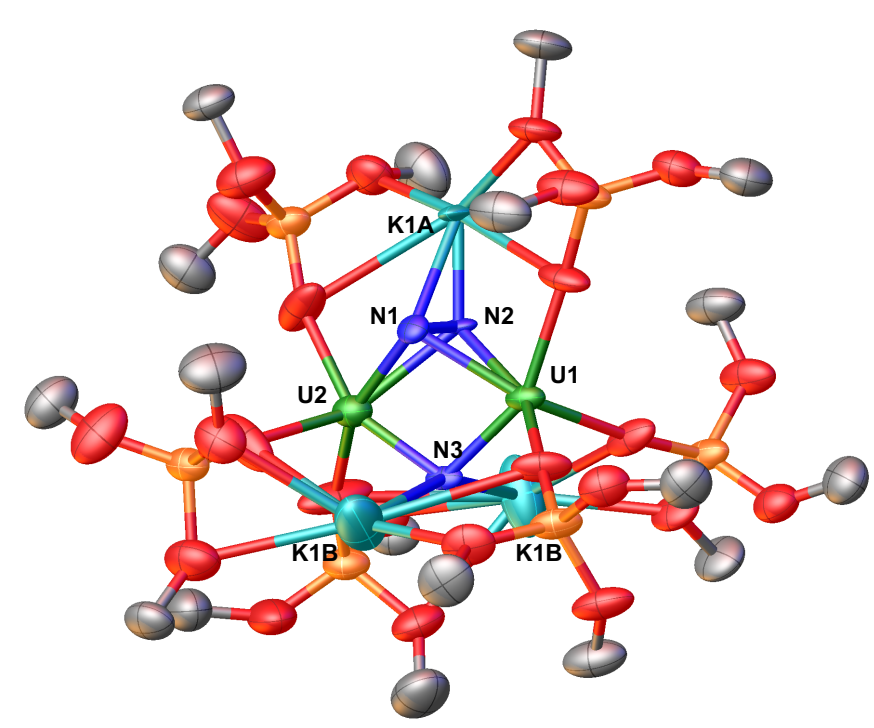

Figure 7: Molecular structure of 46, probab iv at $50 \%$, hydrogen atoms and methy groups are om lted for carty seected bond d stances $|\dot{A}| U_{\text {avg }}-\mathrm{N} 3$, 2.069(3); N1-N2, 1.521 (18

newly formed species. The increased stability of $\left[\mathrm{K}_{3}\left\{\left[\mathrm{U}\left(\mathrm{OSi}\left(\mathrm{O}^{\mathrm{t}} \mathrm{Bu}\right)_{3}\right)_{3}\right]_{2}(\mu-\mathrm{N})\right\}\right], 34$ in solid state and in solution makes it, in fact, a better candidate to investigate the reactivity towards dinitrogen. When complex $\mathbf{3 4}$ is exposed to an atmosphere of $\mathrm{N}_{2}$ in solid state or in a toluene solution, the complex $\left[K_{3}\left\{\left[\mathrm{U}\left(\mathrm{OSi}\left(\mathrm{O}^{\mathrm{t}} \mathrm{Bu}\right)_{3}\right)_{3}\right]_{2}(\mu-N)\left(\mu-\eta^{2}: \eta^{2}-\mathrm{N}_{2}\right)\right\}, 46\right.$ is formed. Dinitrogen undergoes a four-electron reduction to $\mathrm{N}_{2}{ }^{4-}$ concomitantly with the oxidation of each $U$ ion from $U($ III) to $\mathrm{U}(\mathrm{V}){ }^{19 \mathrm{~d}}$ Theoretical investigation suggests that the removal of a $\mathrm{Cs}^{+}$in $\mathbf{3 3}$ is more favourable than the analogue process with $\mathrm{K}^{+}$ in 34.80 Thus, upon the rearrangement of the siloxide framework required to bind $\mathrm{N}_{2}$, decomposition processes are more favoured in 33 than 34 . The $\mathrm{N}_{2}$ binding and functionalization reactivity is summarized in Scheme 22 .

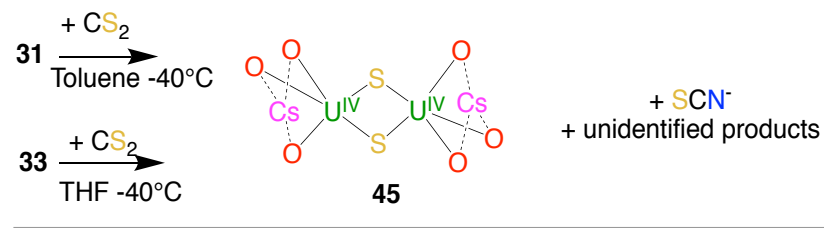

Scheme 21: Reactivity with $\mathrm{CS}_{2}$ of the duran um( $\left.V / H\right)$ and the duran um (I) brdg ng nerde, compexes 31 and 33 .

The oxidation state of the $U$ ions and the extent of dinitrogen reduction in $\mathbf{4 6}$ was confirmed by SQUID magnetometry, EPR, and Raman spectroscopy. The X-ray crystal structure of $\mathbf{4 6}$ (Figure 7) shows that the UNU angle changes from $173.7(8)^{\circ}$ in complex 33 to $106.0(5)^{\circ}$ in complex 46. Such a striking difference in the UNU angle upon binding and reduction of $\mathrm{N}_{2}$ confirms the ability of the siloxide ligands to create a flexible ligand framework which holds together the two uranium centres during the reaction with dinitrogen. Four-electron reduction of dinitrogen is known for group $4 \mathrm{~d}$-metals. ${ }^{81}$ but is unprecedented in $\mathrm{f}$ element chemistry. ${ }^{8 d}$ Moreover, until very recently, $\mathrm{N}_{2}$ functionalization had never been reported for

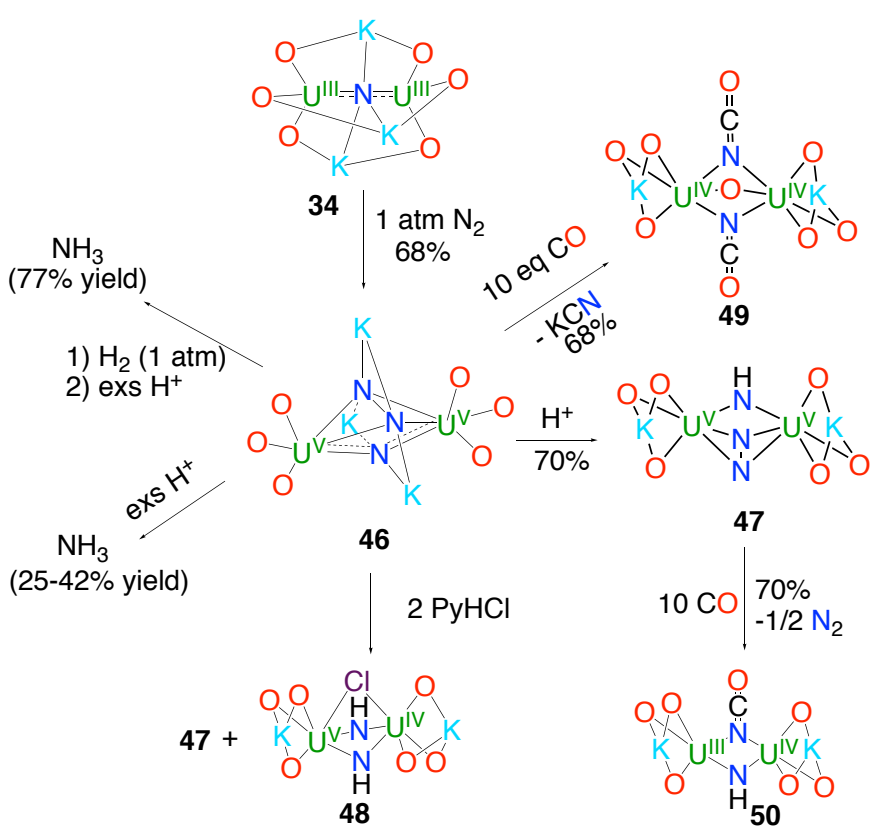

Scheme 22: Reactivity with $\mathrm{N}_{2}$ of the d uran um ( ) br $d_{g} n_{B} n$ tr de 34., affording the nirde hydrazdo brdged duranum ( $V$ ) comoex 46 and its subsequent reactivity with $\mathrm{H}^{+}, \mathrm{CO}$, and $\mathrm{H}_{2}$.

dinitrogen complexes of f-elements which usually undergo $\mathrm{N}_{2}$ displacement upon addition of $\mathrm{H}_{2}$ or $\mathrm{CO}$.

The protonation reaction of the complex 46 with 1 equiv of 2,4,6-tri-tertbutylphenol led only to nitride protonation and to the formation of the mono protonated complex $\left[\mathrm{K}_{2}\left\{\left[\mathrm{U}\left(\mathrm{OSi}\left(\mathrm{O}^{\mathrm{t}} \mathrm{Bu}\right)_{3}\right)_{3}\right]_{2}(\mu-\mathrm{NH})\left(\mu-\eta^{2}: \eta^{2}-\mathrm{N}_{2}\right)\right\}, 47\right.$.

In contrast, when complex $\mathbf{4 6}$ is reacted with stronger acids such as $\mathrm{PyHCl}, \mathrm{HCl}$ or $\mathrm{HBAr}^{\mathrm{F}}$, the protonation of the hydrazido ligand also occurs and crystals of the complex $\left[\mathrm{K}_{2}\left\{\left[\mathrm{U}\left(\mathrm{OSi}\left(\mathrm{O}^{\mathrm{t} B u}\right)_{3}\right)_{3}\right]_{2}(\mu-\mathrm{NH})_{2}(\mu-\mathrm{Cl})\right\}, 48\right.$ have been obtained. Moreover, when 20 equivs of $\mathrm{PyHCl}$ are added to complex 46 and $d_{6}$-dmso is added to the solid crude reaction mixture, ${ }^{14} \mathrm{NH}_{4} \mathrm{Cl}$ can be identified in the reaction mixture by ${ }^{1} \mathrm{H}$ NMR spectroscopy. A mixture of ${ }^{14} \mathrm{NH}_{4} \mathrm{Cl}$ and ${ }^{15} \mathrm{NH}_{4} \mathrm{Cl}$, distinguishable in the ${ }^{1} \mathrm{H}$ NMR spectrum by their different multiplicity, is observed when the reaction is repeated with $\left[\mathrm{K}_{3}\left\{\left[\mathrm{U}\left(\mathrm{OSi}\left(\mathrm{O}^{\mathrm{t}} \mathrm{Bu}\right)_{3}\right)_{3}\right]_{2}(\mu-\mathrm{N})\left(\mu-\eta^{2}: \eta^{2-15} \mathrm{~N}_{2}\right)\right\},{ }^{15} \mathrm{~N}-46\right.$, suggesting that the nitride and hydrazide groups can exchange. The yield in $\mathrm{NH}_{4}{ }^{+}$, detected by quantitative ${ }^{1} \mathrm{H}$ NMR spectroscopy, ranges from $25 \%$ to $42 \%$ depending on the acid used, but can be increased by performing a preliminary reduction of 46 with $\mathrm{H}_{2}$. Hydrogenation of $\mathrm{N}_{2}$ with $\mathrm{H}_{2}$ is a highly desirable feature, even though it has been accomplished only for a few complexes. Complex 46 is completely consumed when exposed to $1 \mathrm{~atm}$ of $\mathrm{H}_{2}$ at RT for 2-3 weeks. The ${ }^{1} \mathrm{H}$ NMR spectrum of the final reaction mixture is uninformative, and no $\mathrm{NH}_{3}$ could be detected in the headspace of the reaction mixture. Nevertheless, when an excess of $\mathrm{HCl}$ in ethereal solution is added to the crude reaction mixture, quantitative ${ }^{1} \mathrm{H} N M R$ spectroscopy in $d_{6}$-dmso reveals the formation of $\mathrm{NH}_{4} \mathrm{Cl}$ in $77 \%$ yield, suggesting that reactivity with $\mathrm{H}_{2}$ actually affords the cleavage of the $\mathrm{N}-\mathrm{N}$ single bond of the hydrazido ligand. ${ }^{19 d}$ 
Reactivity of $\mathbf{4 6}$ and $\mathbf{4 7}$ with CO also provides the first examples of $\mathrm{N}$ functionalization of bound dinitrogen in $f$ element complexes. The reaction of complex $46\left(\mathrm{~K}_{2} \mathrm{UN}\left(\mathrm{N}_{2}\right) \mathrm{U}\right)$ with an excess of $\mathrm{CO}$ affords the complex $\left[\mathrm{K}_{2}\left\{\left[\mathrm{U}\left(\mathrm{OSi}\left(\mathrm{O}^{\mathrm{B}} \mathrm{Bu}\right)_{3}\right)_{3}\right]_{2}(\mu-\mathrm{O})(\mu-\right.\right.$ $\left.\mathrm{NCO})_{2}\right\}$ ], 49 and the concomitant formation of $\mathrm{KCN}$. Thus, both reductive carbonylation and cleavage of the $\mathrm{CO}$ triple bond are achieved by, respectively, the hydrazido and the nitride ligands. The reduced reactivity of the imido ligand in complex 47 compared to the nitride ligand in complex 46 leads to a different reactivity towards $\mathrm{CO}$. In fact, the reaction of complex $\mathbf{4 7}$ with excess $\mathrm{CO}$ affords the mixed valent $\mathrm{U}(\mathrm{III}) / \mathrm{U}(\mathrm{IV})$ complex $\left[\mathrm{K}_{2}\left\{\left[\mathrm{U}\left(\mathrm{OSi}\left(\mathrm{O}^{\mathrm{t}} \mathrm{Bu}\right)_{3}\right)_{3}\right]_{2}(\mu-\mathrm{NH})(\mu-\mathrm{NCO})\right\}, 50\right.$ and free $\mathrm{N}_{2} .{ }^{79}$ Thus, in this case, the addition of $\mathrm{CO}$ leads to disproportionation of the hydrazido ligand. Attempts to reduce $\mathbf{5 0}$ to regenerate the diuranium(III) complex $\mathbf{3 4}$ have not been successful so far. If such reduction could be easily performed, the catalytic generation of cyanate from $\mathrm{CO}$ and $\mathrm{N}_{2}$ may become accessible.

\section{Reactivity of Siloxide-Supported Uranium(III) Oxide Complexes}

\section{$\mathrm{N}_{2}$ activation and functionalization by oxide bridged diuranium(III) complexes}

The highly reducing nature of the $\left[\mathrm{K}_{2}\left\{\left[\mathrm{U}\left(\mathrm{OSi}\left(\mathrm{O}^{\mathrm{t}} \mathrm{Bu}\right)_{3}\right)_{3}\right]_{2}(\mu-\mathrm{O})\right\}\right]$, $\mathrm{K}_{2} \mathrm{U}-\mathrm{O}-\mathrm{U}, 22$ was evidenced by its reactivity with the inert $\mathrm{N}_{2}$ molecule that affords the dinitrogen complex $\left[\mathrm{K}_{2}\left\{\left[\mathrm{U}\left(\mathrm{OSi}\left(\mathrm{O}^{\mathrm{t}} \mathrm{Bu}\right)_{3}\right)_{3}\right]_{2}(\mu-\mathrm{O})\left(\mu-\eta^{2}: \eta^{2}-\mathrm{N}_{2}\right)\right\}\right], \mathbf{5 1 . 6 6}$ The $\mathrm{N}_{2}$ binding and functionalization reactivity of $\mathbf{2 2}$ is summarized in Scheme 23.

The crystallographically determined N-N bond distance together with SQUID magnetometry measurements confirmed the nature of the $U$ centres in $\mathbf{5 1}$ to be $U(V)$, in agreement with the presence of a bound $\mathrm{N}_{2}{ }^{4-}$ ligand. These data suggest a similar degree of activation of the bound $\mathrm{N}_{2}$ in $\mathbf{5 1}$ as that found in the nitride $\mathrm{N}_{2}$ complex 46. However, important differences were found in the reactivity of the bound dinitrogen. The reaction of 51 with 3 equivs of $\mathrm{CO}$ affords the formation of the complex $\left[\mathrm{K}_{2}\left\{\left[\mathrm{U}\left(\mathrm{OSi}\left(\mathrm{O}^{\mathrm{t}} \mathrm{Bu}\right)_{3}\right)_{3}\right]_{2}(\mu-\mathrm{O})_{2}(\mu-\mathrm{NCN})\right\}\right], \mathbf{5 2 . 6 6}$ Such a reactivity is different from the one observed for the complexes $\left[\mathrm{K}_{3}\left\{\left[\mathrm{U}\left(\mathrm{OSi}\left(\mathrm{O}^{\mathrm{t}} \mathrm{Bu}\right)_{3}\right)_{3}\right]_{2}(\mu-\mathrm{N})\left(\mu-\eta^{2}: \eta^{2}-\mathrm{N}_{2}\right)\right\}\right.$,
46,

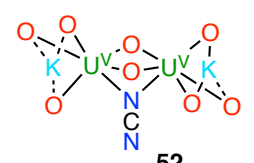

51

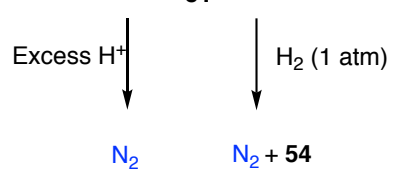

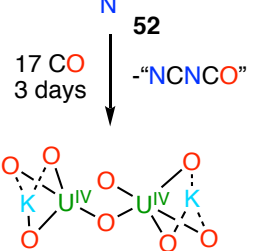

53
Scheme 23. Reactivity with $\mathrm{N}_{2}$ of the duran um ( ) br dg $n g$ oxo 22, affording the oxo hydrazido br dged duranum ( $V$ ) compex 51 and its subsequent reactivity with $\mathrm{CO}, \mathrm{H}_{2}$, and $\mathrm{H}^{+}$

$\left[\mathrm{K}_{2}\left\{\left[\mathrm{U}\left(\mathrm{OSi}\left(\mathrm{O}^{\mathrm{t}} \mathrm{Bu}\right)_{3}\right)_{3}\right]_{2}(\mu-\mathrm{NH})\left(\mu-\eta^{2}: \eta^{2}-\mathrm{N}_{2}\right)\right\}, 47\right.$, in which the formation of cyanate ligands with concomitant reduction of the
$U$ centres was observed. This novel reactivity suggests that the reduction of the $U$ cations in complex $\mathbf{5 1}$ is less accessible, but, when an excess of CO (10-100 equivs) is added, the slow transformation into a new species is observed. In particular the bis $\mathrm{U}(\mathrm{IV})$ complex $\left[\mathrm{K}_{2}\left\{\left[\mathrm{U}\left(\mathrm{OSi}\left(\mathrm{O}^{\mathrm{t} B u}\right)_{3}\right)_{3}\right]_{2}(\mu-\mathrm{O})_{2}\right\}\right], \mathbf{5 3}$ is formed. More surprising is the difference in reactivity compared to complex $\mathbf{4 6}$ observed for reactions with $\mathrm{H}_{2}$ and $\mathrm{H}^{+}$. In both cases, $\mathrm{N}_{2}$ is released from the complex $\mathbf{5 1}$ and no $\mathrm{NH}_{3}$ or $\mathrm{NH}_{4}{ }^{+}$could be detected. In contrast when complex 46 is reacted with $\mathrm{H}^{+}, \mathrm{NH}_{4}{ }^{+}$ is formed with a yield of $25-42 \%$ which is increased to $80 \%$ if $\mathbf{4 6}$ is pre-treated with $\mathrm{H}_{2}$. Moreover, when complex $\mathbf{5 1}$ is reacted with $1 \mathrm{~atm}$ of $\mathrm{H}_{2}$, release of $\mathrm{N}_{2}$ and concomitant formation of the complex $\left[\mathrm{K}_{2}\left\{\left[\mathrm{U}\left(\mathrm{OSi}\left(\mathrm{O}^{\mathrm{t}} \mathrm{Bu}\right)_{3}\right)_{3}\right]_{2}(\mu-\mathrm{O})(\mu-\mathrm{H})_{2}\right\}\right], \mathbf{5 4}$ is observed (see following paragraph for the synthesis and characterization). Such a different reactivity is originated from important differences in the nature of bonding and in the electronic structure of the oxide and nitride complexes. Notably, the measurements of magnetic susceptibility in function of temperature show the presence of antiferromagnetic coupling between the two uranium ions of the nitride bridged complexes 34 and 46 , but show that the oxide bridged counterparts $\mathbf{2 2}$ and $\mathbf{5 1}$ behave as independent paramagnets. Moreover, computational studies show a different binding scheme for the two complexes, with a degree of covalency in the U- $\mathrm{N}_{\text {nitride }}$ bonding but not in the $\mathrm{U}-\mathrm{O}_{\text {oxo }}$ one. Furthermore, while in complex 46 the nitride ligand does participate in the bonding and in the subsequent activation of $\mathrm{N}_{2}$, the oxo ligand in complex $\mathbf{5 1}$ acts as a spectator ligand.

These results show that linkers used to build polymetallic uranium systems can have dramatic electronic effects in dinitrogen activation and functionalization. Cations may also play a role in tuning such differences in reactivity and should be further explored.

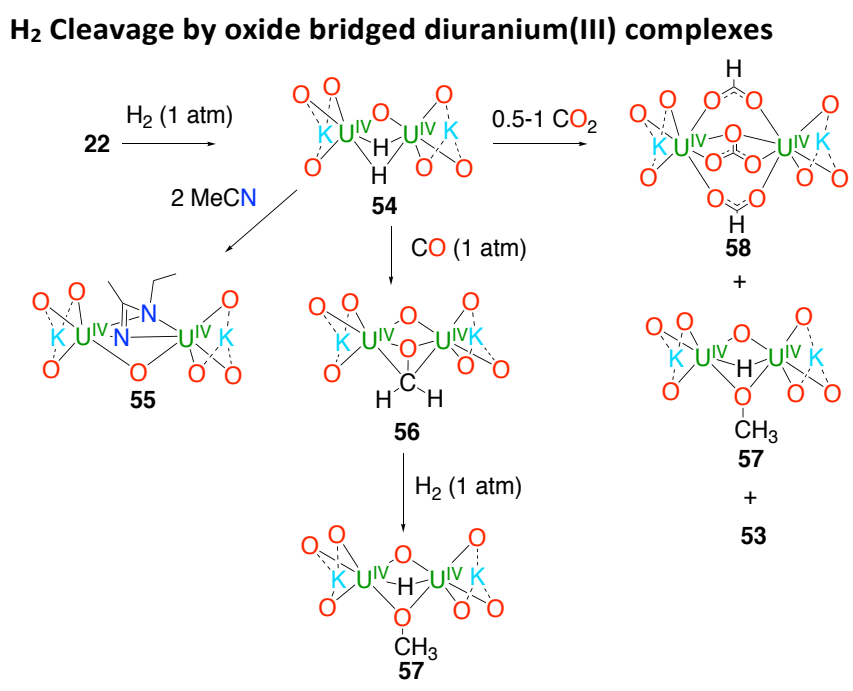

Scheme 24: $\mathrm{H}_{2}$ cleavage by 22, affording the oxo bis-hydride bridged diuranium (V) complex, 54 and is subsequent react $v$ iv $w$ in $C O$, $M e C N$, and Complex $\mathbf{5 4}$ is a rare example of a stable uranium(IV) bis-hydride that can be prepared from the reaction of 22 with $1 \mathrm{~atm}$ of $\mathrm{H}_{2} .{ }^{82}$ The bis hydride complex 54 shows a remarkable stability 
towards $\mathrm{H}_{2}$ release, making it an attractive candidate for being used in hydride transfer reactivity. Notably, the reaction of $\mathbf{5 4}$ with 2 equivs of $\mathrm{MeCN}$ afforded the complex $\left[\mathrm{K}_{2}\left\{\left[\mathrm{U}\left(\mathrm{OSi}\left(\mathrm{O}^{\mathrm{t}} \mathrm{Bu}\right)_{3}\right)_{3}\right]_{2}(\mu-\mathrm{O})\left(\mu-\kappa^{2}-\mathrm{NC}\left(\mathrm{CH}_{3}\right) \mathrm{NCH}_{2} \mathrm{CH}_{3}\right)\right\}\right]$, (Scheme 24) where the reductive coupling of two acetonitrile molecules has occurred following hydride transfer from the uranium to the nitrile. The reaction between complex $\mathbf{5 4}$ and 1 equiv of $\mathrm{CO}$ affords the oxomethylene complex $\left[\mathrm{K}_{2}\left\{\left[\mathrm{U}\left(\mathrm{OSi}\left(\mathrm{O}^{\mathrm{t}} \mathrm{Bu}\right)_{3}\right)_{3}\right]_{2}(\mu-\mathrm{O})\left(\mu-\mathrm{CH}_{2} \mathrm{O}\right)\right\}\right], 56$ trough the fourelectron reduction of $\mathrm{CO}$ and the concomitant oxidation of the two hydride bridging ligands. Complex 56 was found to irreversibly cleave $\mathrm{H}_{2}$ in ambient conditions to afford the methoxide complex $\left[\mathrm{K}_{2}\left\{\left[\mathrm{U}\left(\mathrm{OSi}\left(\mathrm{O}^{\mathrm{t}} \mathrm{Bu}\right)_{3}\right)_{3}\right]_{2}(\mu-\mathrm{O})(\mu-\mathrm{H})\left(\mu-\mathrm{CH}_{3} \mathrm{O}\right)\right\}\right]$, 57 in $75 \%$ yield. 82

Complex 54 also effect the direct reduction of $\mathrm{CO}_{2}$ to methoxide which the first example of such reactivity in f-element chemistry.

These results show that polynuclear oxide-supported hydrides are excellent candidates for the conversion of $\mathrm{CO}$ and $\mathrm{CO}_{2}$ to methoxide. These systems also provide competent models of the surface mediated hydride transfer to $\mathrm{CO}$ or $\mathrm{CO}_{2}$ at metal oxide surfaces in the heterogeneously catalysed FischerTropsch process. The transformation of $\mathrm{H}_{2}$ an $\mathrm{CO}$ into methanol could be driven catalytically if conditions for the addition of $\mathrm{H}_{2}$ to complex $\mathbf{5 7}$ could be identified.

\section{Conclusions}

The tris- tertbutoxysiloxide ligand has proven to be particularly well suited to support the formation of stable homo and heteropolymetallic complexes of uranium that have shown high ligand and metal-based reactivity towards small molecule fixation and functionalization. These simple ligands allow, by binding several metals, to build flexible frameworks for the multimetallic cooperative binding and activation of small molecules. The role of the ligand electronics and of nature of the counterion in reactivity remains ambiguous and comparative studies using other simple ligands and diverse counterions will be required to further understand it.

The presented results show that the reactivity of the uranium(III) complexes supported by siloxide ligands can be tuned simply by changing the number of ligands. We have shown that, in mononuclear complexes, the increase in number of ligands allows to increase the steric hinderance which does not result in reduced reactivity but facilitates the removal of the $\mathrm{CO}_{2}$ or $\mathrm{CS}_{2}$ reduction products from the uranium coordination sphere. These experiments suggest that catalytic cycles should be easily implemented without strong coordination of reduction products such as carbonate or thiocarbonate being a limitation. Analogous synthetic cycles were implemented for the reduction of $\mathrm{CO}_{2}$ to carbonate and $\mathrm{CO}$ by uranium(III) complexes supported by bulky polydentate amine-phenolate ligands, ${ }^{5 a}$ but in the non-optimized conditions carbonate binding by uranium leads to insoluble products and to the termination of the cycle. Ideally, one should be able to drive such reactions electrochemically. The first example of the use uranium(III) compounds in electrocatalysis was recently reported for the $\mathrm{H}_{2}$ production from $\mathrm{H}_{2} \mathrm{O}^{6}$ and it can be anticipated that use of uranium(III) compounds as electrocatalysts can be extended to $\mathrm{CO}_{2}$ and $\mathrm{N}_{2}$ reduction.

The use of simple nitride and oxide linkers for assembling compounds containing more than one uranium(III) centre allowed to demonstrate that an unique reactivity results from the cooperative binding of dinitrogen or hydrides by two uranium cations. Notably, the four electrons reduction of dinitrogen is promoted by both the oxo- and nitride bridged diuranium(III) complexes affording diuranium(V) complexes of $\mathrm{N}_{2}{ }^{4-}$. Moreover, it is remarkable that the uranium-bound dinitrogen can be functionalized by $\mathrm{CO}, \mathrm{CO}_{2}$ and even $\mathrm{H}_{2}$ and in some cases results in the reduction of the uranium centers. In these stoichiometric processes, new molecules, such as cyanate and cyanamide, are built from readily available substrates (CO and $\mathrm{N}_{2}$ ). Despite the fact that $\mathrm{N}_{2}$ functionalization was also reported for group 4 metals, ${ }^{81}$ the increased redox flexibility of uranium renders its compounds well suited for developing catalytic cycles (chemical and electrochemical). The nitride linker is involved in the reactivity of the dinuclear dinitrogen complexes but the more robust oxide linker may be implemented in catalytic cycles for the transformation of small molecules if the system electronics can be properly tuned.

Very recently, we have shown that replacement of siloxides with amide ligands leads to very different reactivity of the uranium bound nitride. ${ }^{83}$ We foresee that a careful combined tuning of the electronics of the linkers and ancillary ligand should lead to systems where reducing reactants such as hydrogen or CO may be used to restore the uranium(III) precursor alone or in combination with reducing agents. Such studies should open the way to the development of uraniumbased catalysts for dinitrogen functionalization and provide a better understanding of dinitrogen reduction by polymetallic compounds.

\section{Conflicts of interest}

"There are no conflicts to declare".

\section{Acknowledgements}

We acknowledge support from the Swiss National Science Foundation grant number 200021_162430 and 00021_178793 and from the Ecole Polytechnique Fédérale de Lausanne (EPFL).

\section{Notes and references}

1. (a)M. Aresta, Carbon Dioxide as a Chemical Feedstock, Wiley VCH, 2010; (b)E. E. Benson, C. P. Kubiak, A. J. Sathrum and J. M. Smieja, Chem. Soc. Rev., 2009, 38, 89-99.

2. (a)H. Liu, T. Ghatak and M. S. Eisen, Chem. Commun., 2017, 53, 11278-11297; (b)A. R. Fox, S. C. Bart, K. Meyer and C. C. Cummins, Nature, 2008, 455, 341-349. 
3. P. L. Arnold, S. M. Mansell, L. Maron and D. McKay, Nat. Chem., 2012, 4, 668-674.

4. (a)I. Castro-Rodriguez, H. Nakai, L. N. Zakharov, A. L. Rheingold and K. Meyer, Science, 2004, 305, 17571759; (b)A. S. P. Frey, F. G. N. Cloke, M. P. Coles, L. Maron and T. Davin, Angew. Chem. Int. Ed. Engl., 2011, 50, 6881-6883; (c)H. S. La Pierre and K. Meyer, in Prog. Inorg. Chem., ed. K. D. Karlin, JOHN WILEY \& SONS INC, HOBOKEN, 2014, vol. 58, pp. 303-415; (d)V. Mougel, C. Camp, J. Pecaut, C. Coperet, L. Maron, C. E. Kefalidis and M. Mazzanti, Angew. Chem. Int. Ed. Engl., 2012, 51, 12280-12284.

5. (a)A. C. Schmidt, A. V. Nizovtsev, A. Scheurer, F. W. Heinemann and K. Meyer, Chem. Commun., 2012, 48, 8634-8636; (b)B. M. Gardner, J. C. Stewart, A. L. Davis, J. McMaster, W. Lewis, A. J. Blake and S. T. Liddle, Proc Natl Acad Sci USA, 2012, 109, 9265-9270.

6. D. P. Halter, F. W. Heinemann, J. Bachmann and K. Meyer, Nature, 2016, 530, 317-321.

7. Haber, F Ammonia German patent DE 229126 Pat., 1909.

8. (a)P. L. Arnold and Z. R. Turner, Nat. Rev. Chem., 2017, 1; (b)P. L. Arnold, Chem. Commun., 2011, 47, 90059010; (c)B. M. Gardner and S. T. Liddle, Eur. J. Inorg. Chem., 2013, 2013, 3753-3770; (d)M. D. Walter, in Advances in Organometallic Chemistry, Vol 65, ed. P. J. Perez, 2016, vol. 65, pp. 261-377; (e)O. T. Summerscales and F. G. N. Cloke, in Organometallic and Coordination Chemistry of the Actinides, ed. T. E. AlbrechtSchmitt, 2008, vol. 127, pp. 87-117; (f)S. C. Bart and K. Meyer, in Struct. Bond., 2008, vol. 127, pp. 119-176; (g)T. Andrea and M. S. Eisen, Chem. Soc. Rev., 2008, 37, 550-567; (h)S. T. Liddle, Angew. Chem. Int. Ed. Engl., 2015, 54, 8604-8641.

9. (a)J. G. Brennan, R. A. Andersen and J. L. Robbins, J. Am. Chem. Soc., 1986, 108, 335-336; (b)J. Parry, E. Carmona, C. Simon and M. Hursthouse, J. Am. Chem. Soc., 1995, 117, 2649-2650; (c)W. J. Evans, S. A. Kozimor, G. W. Nyce and J. W. Ziller, J. Am. Chem. Soc., 2003, 125, 13831-13835.

10. W. J. Evans, S. A. Kozimor and J. W. Ziller, J. Am. Chem. Soc., 2003, 125, 14264-14265.

11. I. Castro-Rodriguez and K. Meyer, J. Am. Chem. Soc., 2005, 127, 11242-11243.

12. O. T. Summerscales, A. S. P. Frey, F. Geoffrey, N. Cloke and P. B. Hitchcock, Chem. Commun., 2009, 198-200.

13. J. G. Brennan, R. A. Andersen and A. Zalkin, Inorg. Chem., 1986, 25, 1756-1760.

14. O. T. Summerscales, F. G. N. Cloke, P. B. Hitchcock, J. C. Green and N. Hazari, Science, 2006, 311, 829-831.

15. P. Roussel and P. Scott, J. Am. Chem. Soc., 1998, 120, 1070-1071.

16. P. L. Arnold, Z. R. Turner, R. M. Bellabarba and R. P. Tooze, Chem. Sci., 2011, 2, 77-79.

17. O. T. Summerscales, F. G. N. Cloke, P. B. Hitchcock, J. C. Green and N. Hazari, J. Am. Chem. Soc., 2006, 128, 9602-9603.

18. (a)S. M. Mansell, N. Kaltsoyannis and P. L. Arnold, J. Am. Chem. Soc., 2011, 133, 9036-9051; (b)G. Cloke, F. N. and P. B. Hitchcock, J. Am. Chem. Soc., 2002, 124, 9352-9353.
19.

(a)O. Cooper, C. Camp, J. Pécaut, C. E. Kefalidis, L. Maron, S. Gambarelli and M. Mazzanti, J. Am. Chem. Soc., 2014, 136, 6716-6723; (b)A. L. Odom, P. L. Arnold and C. C. Cummins, J. Am. Chem. Soc., 1998, 120, 58365837; (c)P. L. Arnold, C. J. Stevens, N. L. Bell, R. M. Lord, J. M. Goldberg, G. S. Nichol and J. B. Love, Chem. Sci., 2017, 8, 3609-3617; (d)M. Falcone, L. Chatelain, R. Scopelliti, I. Zivkovic and M. Mazzanti, Nature, 2017, 547, 332-335.

20. I. Korobkov, S. Gambarotta and G. P. A. Yap, Angew. Chem. Int. Ed. Engl., 2002, 41, 3433-3436.

21. (a)P. T. Wolczanski, Polyhedron, 1995, 14, 3335-3362; (b)D. R. Neithamer, R. E. Lapointe, R. A. Wheeler, D. S. Richeson, G. D. Vanduyne and P. T. Wolczanski, J. Am. Chem. Soc., 1989, 111, 9056-9072; (c)C. Krempner, Eur. J. Inorg. Chem., 2011, 1689-1698.

22. (a)T. J. Boyle and L. A. M. Ottley, Chem. Rev., 2008, 108, 1896-1917; (b)A. Willauer, D. Toniolo, F. FadaeiTirani, Y. Yang, S. Laurent and M. Mazzanti, J. Chem. Soc.-Dalton Trans., 2019, DOI: 10.1039/c1039dt00554d; (c)R. P. Kelly, D. Toniolo, F. F. Tirani, L. Maron and M. Mazzanti, Chem. Commun., 2018, 54, 10268-10271; (d)R. P. Kelly, L. Maron, R. Scopelliti and M. Mazzanti, Angew. Chem. Int. Ed. Engl., 2017, 56, 15663-15666; (e)J. Andrez, J. Pecaut, P.-A. Bayle and M. Mazzanti, Angew. Chem. Int. Ed. Engl., 2014, 53, 10448-10452; (f)D. Toniolo, A. Willauer, R. Scopelliti, J. Andrez, Y. Yang and L. Maron, Chem. Eur. J., 2019; (g)V. Lorenz, A. Fischer, S. Giessmann, J. W. Gilje, Y. Gun'ko, K. Jacob and F. T. Edelmann, Coord. Chem. Rev., 2000, 206, 321-368; (h)G. Lapadula, M. P. Conley, C. Coperet and R. A. Andersen, Organometallics, 2015, 34, 2271-2277.

23. S. M. Mansell, J. H. Farnaby, A. I. Germeroth and P. L. Arnold, Organometallics, 2013, 32, 4214-4222.

24. (a)S. Lysenko, B. Haberlag, C. G. Daniliuc, P. G. Jones and M. Tamm, Chemcatchem, 2011, 3, 115-118; (b)J. Jarupatrakorn and T. D. Tilley, J. Chem. Soc.-Dalton Trans., 2004, 2808-2813; (c)K. L. Fujdala and T. D. Tilley, Chem. Mater., 2001, 13, 1817-1827; (d)F. Blanc, C. Coperet, J. Thivolle-Cazat, J. M. Basset, A. Lesage, L. Emsley, A. Sinha and R. R. Schrock, Angew. Chem. Int. Ed. Engl., 2006, 45, 1216-1220; (e)D. Werner and R. Anwander, J. Am. Chem. Soc., 2018, 140, 14334-14341; (f)K. L. Fujdala and T. D. Tilley, Chem. Mater., 2004, 16, 1035-1047; (g)M. P. Coles, C. G. Lugmair, K. W. Terry and T. D. Tilley, Chem. Mater., 2000, 12, 122-131.

25. (a)J. Friedrich, Y. S. Qiao, C. Maichle-Mossmer, E. J. Schelter and R. Anwander, J. Chem. Soc.-Dalton Trans., 2018, 47, 10113-10123; (b)J. Friedrich, C. MaichleMossmer and R. Anwander, Chem. Commun., 2017, 53, 12044-12047; (c)M. Nishiura, Z. M. Hou and Y. Wakatsuki, Organometallics, 2004, 23, 1359-1368; (d)Z. M. Hou and Y. Wakatsuki, J. Organomet. Chem., 2002, 647, 61-70; (e)A. Fischbach, M. G. Klimpel, M. Widenmeyer, E. Herdtweck, W. Scherer and R. Anwander, Angew. Chem. Int. Ed. Engl., 2004, 43, 2234-2239.

26. C. Camp, L. Chatelain, C. E. Kefalidis, J. Pecaut, L. Maron and M. Mazzanti, Chem. Commun., 2015, 51, 15454-15457. 
C. Camp, J. Pecaut and M. Mazzanti, J. Am. Chem. Soc. 2013, 135, 12101-12111.

28. C. Camp, C. E. Kefalidis, J. Pecaut, L. Maron and M. Mazzanti, Angew. Chem. Int. Ed. Engl., 2013, 52, 12646-12650.

29. C. Bianchini, C. Mealli, A. Meli, A. Orlandini and L. Sacconi, Angewandte Chemie-International Edition in English, 1979, 18, 673-674.

30. (a)O. P. Lam and K. Meyer, Polyhedron, 2012, 32, 1-9; (b)O. P. Lam, F. W. Heinemann and K. Meyer, Angew. Chem. Int. Ed. Engl., 2011, 50, 5965-5968.

31. O. P. Lam, L. Castro, B. Kosog, F. W. Heinemann, L. Maron and K. Meyer, Inorg. Chem., 2012, 51, 781-783. C. Camp, O. Cooper, J. Andrez, J. Pecaut and M Mazzanti, J. Chem. Soc.-Dalton Trans., 2015, 44, 26502656.

33. O. P. Lam, S. C. Bart, H. Kameo, F. W. Heinemann and K. Meyer, Chem. Commun., 2010, 46, 3137-3139.

34. (a)L. Castro, O. P. Lam, S. C. Bart, K. Meyer and L. Maron, Organometallics, 2010, 29, 5504-5510; (b)L. Castro, C. E. Kefalidis, D. McKay, S. Essafi, L. Perrin and L. Maron, J. Chem. Soc.-Dalton Trans., 2014, 43, 1212412134.

35. (a)N. Tsoureas, L. Castro, A. F. R. Kilpatrick, F. G. N. Cloke and L. Maron, Chem. Sci., 2014, 5, 3777-3788; (b)C. J. Inman, A. S. P. Frey, A. F. R. Kilpatrick, F. G. N. Cloke and S. M. Roe, Organometallics, 2017, 36, 45394545; (c)A.-C. Schmidt, F. W. Heinemann, C. E. Kefalidis, L. Maron, P. W. Roesky and K. Meyer, Chem. Eur. J., 2014, 20, 13501-13506.

36. R. J. Kahan, J. H. Farnaby, N. Tsoureas, F. G. N. Cloke, P. B. Hitchcock, M. P. Coles, S. M. Roe and C. Wilson, J. Organomet. Chem., 2018, 857, 110-122.

37. (a)C. Camp, M. A. Antunes, G. Garcia, I. Ciofini, I. C. Santos, J. Pecaut, M. Almeida, J. Marcalo and M. Mazzanti, Chem. Sci., 2014, 5, 841-846; (b)D. M. King, F. Tuna, E. J. L. Mclnnes, J. McMaster, W. Lewis, A. J. Blake and S. T. Liddle, Science, 2012, 337, 717-720; (c)J. G. Brennan and R. A. Andersen, J. Am. Chem. Soc., 1985, 107, 514-516; (d)D. S. J. Arney and C. J. Burns, J. Am. Chem. Soc., 1993, 115, 9840-9841; (e)I. CastroRodriguez and K. Meyer, Chem. Commun., 2006, 13531368; (f)W. J. Evans and S. A. Kozimor, Coord. Chem. Rev., 2006, 250, 911-935; (g)C. R. Graves and J. L. Kiplinger, Chem. Commun., 2009, 3831-3853.

38. S. Fortier, J. L. Brown, N. Kaltsoyannis, G. Wu and T. W. Hayton, Inorg. Chem., 2012, 51, 1625-1633.

39. A. J. Lewis, P. J. Carroll and E. J. Schelter, J. Am. Chem. Soc., 2013, 135, 511-518.

40. S. C. Bart, C. Anthon, F. W. Heinemann, E. Bill, N. M. Edelstein and K. Meyer, J. Am. Chem. Soc., 2008, 130, 12536-12546.

41. S. Gambarotta, F. Arena, C. Floriani and P. F. Zanazzi, J. Am. Chem. Soc., 1982, 104, 5082-5092.

42. M. Ephritikhine, Coord. Chem. Rev., 2016, 319, 35-62.

43. (a)O. P. Lam, F. W. Heinemann and K. Meyer, Chem. Sci., 2011, 2, 1538-1547; (b)J. L. Brown, G. Wu and T. W. Hayton, Organometallics, 2013, 32, 1193-1198; (c)D. E. Smiles, G. Wu and T. W. Hayton, New J. Chem. 2015, 39, 7563-7566; (d)J. G. Brennan, R. A. Andersen and A. Zalkin, Inorg. Chem., 1986, 25, 1761-1765.
44.

45.

.

(a)V. Mougel, J. Pecaut and M. Mazzanti, Chem. Commun., 2012, 48, 868-870; (b)V. Mougel, P. Horeglad, G. Nocton, J. Pécaut and M. Mazzanti, Chem. Eur. J., 2010, 16, 14365-14377; (c)P. L. Arnold, J. B. Love and D. Patel, Coord. Chem. Rev., 2009, 253, 19731978.

59. (a)T. W. Hayton, Chem. Commun., 2013, 49, 29562973; (b)D. M. King and S. T. Liddle, Coord. Chem. Rev., 2014, 266, 2-15.

60. G. W. C. Silva, C. B. Yeamans, A. P. Sattelberger, T. Hartmann, G. S. Cerefice and K. R. Czerwinski, Inorg. Chem., 2009, 48, 10635-10642.

61. (a)G. Nocton, J. Pecaut and M. Mazzanti, Angew. Chem. Int. Ed. Engl., 2008, 47, 3040-3042; (b)W. J. Evans, S. A. Kozimor and J. W. Ziller, Science, 2005, 309, 1835-1838.

62. A. R. Fox, P. L. Arnold and C. C. Cummins, J. Am. Chem. Soc., 2010, 132, 3250-3251. 
63.

(a)S. Fortier, G. Wu and T. W. Hayton, J. Am. Chem. Soc., 2010, 132, 6888-6889; (b)L. Maria, I. C. Santos, V. R. Sousa and J. Marcalo, Inorg. Chem., 2015, 54, 91159126; (c)D. M. King, F. Tuna, E. J. L. Mclnnes, J. McMaster, W. Lewis, A. J. Blake and S. T. Liddle, Nat. Chem., 2013, 15, 482-488; (d)D. M. King, J. McMaster, F. Tuna, E. J. L. Mclnnes, W. Lewis, A. J. Blake and S. T. Liddle, J. Am. Chem. Soc., 2014, 136, 5619-5622; (e)P. A. Cleaves, D. M. King, C. E. Kefalidis, L. Maron, F. Tuna, E. J. L. McInnes, J. McMaster, W. Lewis, A. J. Blake and S. T. Liddle, Angew. Chem. Int. Ed. Engl., 2014, 53, 10412-10415; (f)L. Chatelain, R. Scopelliti and M. Mazzanti, J. Am. Chem. Soc., 2016, 138, 1784-1787; (g)D. M. King, P. A. Cleaves, A. J. Wooles, B. M. Gardner, N. F. Chilton, F. Tuna, W. Lewis, E. J. L. McInnes and S. T. Liddle, Nat. Commun., 2016, 7; (h)N. Tsoureas, A. F. R. Kilpatrick, C. J. Inman and F. G. N. Cloke, Chem. Sci., 2016, 7, 4624-4632.

64. R. K. Thomson, T. Cantat, B. L. Scott, D. E. Morris, E. R. Batista and J. L. Kiplinger, Nat. Chem., 2010, 2, 723729.

65. J. Du, D. M. King, L. Chatelain, F. Tuna, E. J. L. McInnes, A. J. Wooles, L. Maron and S. T. Liddle, Chem. Sci., 2019, 10, 3738-3745.

66. M. Falcone, L. Barluzzi, J. Andrez, F. F. Tirani, I. Zivkovic, A. Fabrizio, C. Corminboeuf, K. Severin and M. Mazzanti, Nat. Chem., 2019, 11, 154-160.

67. S. D. Roughley and A. M. Jordan, J. Med. Chem., 2011, 54, 3451-3479.

68. M. Aresta and A. Dibenedetto, J. Chem. Soc.-Dalton Trans., 2007, 2975-2992.

69. (a)R. J. Burford and M. D. Fryzuk, Nature Reviews Chemistry, 2017, 1, Article Number: UNSP 0026; (b)M. P. Shaver and M. D. Fryzuk, Adv. Synth. Catal., 2003, 345, 1061-1076.

70. (a)D. J. Knobloch, E. Lobkovsky and P. J. Chirik, Nat. Chem., 2010, 2, 30-35; (b)M. D. Fryzuk, J. B. Love, S. J. Rettig and V. G. Young, Science, 1997, 275, 1445-1447.

71. (a)S. P. Semproni and P. J. Chirik, J. Am. Chem. Soc., 2013, 135, 11373-11383; (b)S. P. Semproni and P. J. Chirik, Angew. Chem. Int. Ed. Engl., 2013, 52, 1296512969; (c)J. S. Silvia and C. C. Cummins, J. Am. Chem. Soc., 2010, 132, 2169-2170; (d)J. M. Smith, Prog. Inorg. Chem., 2014, 58, 417-470.

72. (a)B. Askevold, J. T. Nieto, S. Tussupbayev, M. Diefenbach, E. Herdtweck, M. C. Holthausen and S. Schneider, Nat. Chem., 2011, 3, 532-537; (b)J. J. Scepaniak, R. P. Bontchev, D. L. Johnson and J. M. Smith, Angew. Chem. Int. Ed. Engl., 2011, 50, 66306633; (c)B. L. Tran, M. Singhal, H. Park, O. P. Lam, M. Pink, J. Krzystek, A. Ozarowski, J. Telser, K. Meyer and D. J. Mindiola, Angew. Chem. Int. Ed. Engl., 2010, 49, 9871-9875; (d)J. S. Silvia and C. C. Cummins, J. Am. Chem. Soc., 2009, 131, 446-447; (e)S. P. Semproni, C. Milsmann and P. J. Chirik, Angew. Chem. Int. Ed. Engl., 2012, 51, 5213-5216.

73. I. Klopsch, M. Kinauer, M. Finger, C. Wurtele and S. Schneider, Angew. Chem. Int. Ed. Engl., 2016, 55, 4786-4789.

74. P. A. Cleaves, C. E. Kefalidis, B. M. Gardner, F. Tuna, E. J. L. Mclnnes, W. Lewis, L. Maron and S. T. Liddle, Chem. Eur. J., 2017, 23, 2950-2959.
75.

76.

77.

78.

79.

80.

81.

2007, 46, 3180-3183.

82. M. Falcone, R. Scopelliti and M. Mazzanti, J. Am. Chem. Soc., 2019, 141, 9570-9577.

83. C. T. Palumbo, L. Barluzzi, R. Scopelliti, I. Zivkovic, A. Fabrizio, C. Corminboeuf and M. Mazzanti, Chem. Sci., 2019, https://doi.org/10.1039/C1039SC02149C. 
Table of contents:

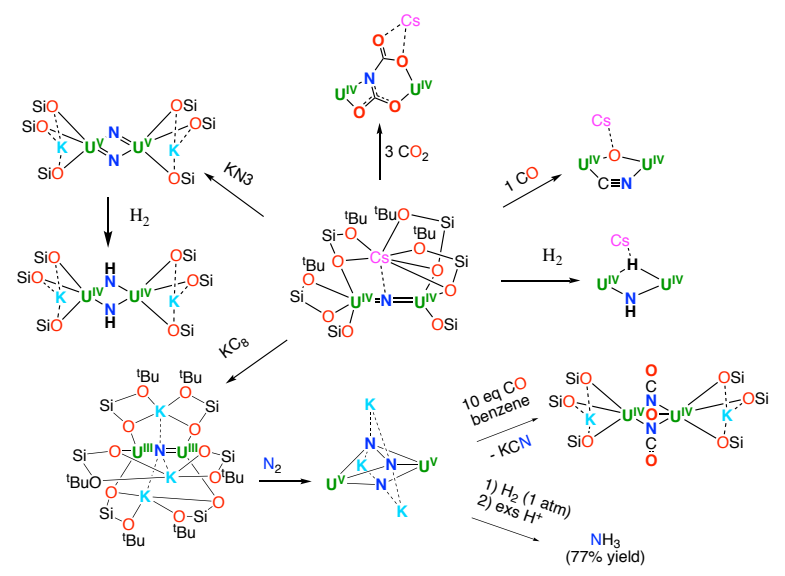

An overview of the small molecule activation chemistry of polynuclear complexes of uranium supported by the tertbutoxysiloxide ligand. 